\title{
GCU
}

Glasgow Caledonian

University

University for the Common Good

\section{A vectorized bimodal distribution based micro differential evolution algorithm (VB- $\mathrm{mDE}$ )}

Chen, Xu; Miao, Xueliang; Tianfield, Huaglory

Published in:

Multiagent and Grid Systems

DOI:

10.3233/MGS-200331

Publication date:

2020

Document Version

Author accepted manuscript

Link to publication in ResearchOnline

Citation for published version (Harvard):

Chen, X, Miao, X \& Tianfield, H 2020, 'A vectorized bimodal distribution based micro differential evolution algorithm (VB-mDE)', Multiagent and Grid Systems, vol. 16, no. 3, pp. 245-261. https://doi.org/10.3233/MGS200331

\section{General rights}

Copyright and moral rights for the publications made accessible in the public portal are retained by the authors and/or other copyright owners and it is a condition of accessing publications that users recognise and abide by the legal requirements associated with these rights.

Take down policy

If you believe that this document breaches copyright please view our takedown policy at https://edshare.gcu.ac.uk/id/eprint/5179 for details of how to contact us. 


\section{GCU}

Glasgow Caledonian

University

University for the Common Good

\section{A vectorized bimodal distribution based micro differential evolution algorithm (VB- $\mathrm{mDE})$}

Chen, Xu; Miao, Xueliang; Tianfield, Huaglory

Published in:

Multiagent and Grid Systems

Publication date:

2020

Document Version

Peer reviewed version

Link to publication in ResearchOnline

Citation for published version (Harvard):

Chen, X, Miao, X \& Tianfield, H 2020, 'A vectorized bimodal distribution based micro differential evolution algorithm (VB-mDE)', Multiagent and Grid Systems, vol. 16, no. 3.

\section{General rights}

Copyright and moral rights for the publications made accessible in the public portal are retained by the authors and/or other copyright owners and it is a condition of accessing publications that users recognise and abide by the legal requirements associated with these rights.

Take down policy

If you believe that this document breaches copyright please view our takedown policy at https://edshare.gcu.ac.uk/id/eprint/5179 for details of how to contact us. 


\title{
A Vectorized Bimodal Distribution based Micro Differential Evolution Algorithm (VB-mDE)
}

\author{
$\mathrm{Xu}_{\text {CHEN }}^{\mathrm{a}, 1}$, Xueliang MIAO ${ }^{\mathrm{b}}$ and Hugo TIANFIELD ${ }^{\mathrm{c}}$ \\ ${ }^{a}$ School of Electrical and Information Engineering, Jiangsu University, Zhenjiang \\ 212013, Jiangsu, China \\ ${ }^{\mathrm{b}}$ China Nuclear Power Technology Corporation, LTD, Wuhan, 430223, Hubei, China \\ ${ }^{\mathrm{c}}$ School of Computing, Engineering and Built Environment, Glasgow Caledonian \\ University, Glasgow G4 OBA, UK
}

\begin{abstract}
Micro differential evolution (mDE) refers to algorithms that evolve with a small population to search for good solutions. Although mDEs are very useful for resource-constrained optimization tasks, the research on mDEs is still limited. In this paper, we propose a new $\mathrm{mDE}$, i.e., vectorized bimodal distribution based $\mathrm{mDE}$ (called VB-mDE). The main idea is to employ a vectorized bimodal distribution parameter adjustment mechanism in $\mathrm{mDE}$ for performance enhancement. Specifically, in the VB-mDE, two important control parameters, i.e., scale factor $F$ and crossover rate $C R$, are adjusted by bimodal Cauchy distribution. At the same time, to increase the population diversity, the scale factor $F$ is vectorized. The proposed VB-mDE is evaluated on the CEC2014 benchmark functions and compared with the state-of-the-art mDEs and normal DEs. The results show that the proposed VB-mDE has advantages in terms of solution accuracy and convergence speed.
\end{abstract}

Keywords. Micro differential evolution, small population, bimodal distribution, vectorized bimodal Cauchy distribution, parameter adjustment mechanism

\section{Introduction}

Differential evolution (DE) is one of the most powerful evolutionary algorithms for global optimization problems [1] . During the past two decades, DE has received much attention due to its attractive characteristics such as simplicity, speediness and robustness. DE has also been successfully applied to solve various scientific and engineering problems, such as chemical process optimization [2], economic load dispatch [3], and flow shop scheduling [4].

Normal DEs usually works on a large population size [5]. With a large population size, DE has better population diversity during the search process, and also has a higher opportunity to achieve global solutions for complex problems. However, for the resourceconstrained problems like on-line nonlinear model predictive control (NMPC) [6] or real-

${ }^{1}$ Corresponding Author: School of Electrical and Information Engineering, Jiangsu University, Zhenjiang 212013, Jiangsu, China; E-mail:xuchen@ujs.edu.cn 
time vehicle navigation system [7], the computing resources available for population reevaluation in one iteration are largely restricted. In such circumstances, DEs with large population may become ineffective.

Recently, micro-DE (mDE) algorithms, also called as $\mu \mathrm{DE}$, have been proposed as good alternatives. mDE utilizes a small population size, which is often set under 10 . They have fast convergence speed, and can be implemented in the resource-constrained problems, e.g., online applications. However, mDE often suffers premature convergence and stagnation due to the lack of population diversity. To overcome the weakness, several modified $\mathrm{mDE}$ algorithms have been developed [8,9,10,11,12,13,14] .

Although $\mathrm{mDE}$ algorithms can be very useful on the special scenarios, the research on the mDE algorithms is still little compared to normal DE algorithms. On the other hand, it is recognized that the parameter adjustment mechanism (PAM) has important impacts on the performance of DE algorithms [15,16].

In this paper, we focus on advanced PAM for mDE algorithms. Specifically, using vectorized bimodal distribution based PAM (VB-PAM), we propose a novel vectorized bimodal distribution based micro- $\underline{\mathrm{DE}}$ (VB-mDE). In VB-mDE, two important control parameters, i.e., scale factor $F$ and crossover rate $C R$, are adjusted by bimodal Cauchy distribution. At the same time, to increase the population diversity, the bimodal distribution of scale factor $F$ is vectorized.

The bimodal distribution based PAM is taken from the normal DE algorithm in the literature [17]. In this paper, we will show how the bimodal distribution based PAM can be used to design novel $\mathrm{mDE}$ algorithm. Our proposed VB-mDE will be compared with several state-of-the-art $\mathrm{mDE}$ and normal DE algorithms on the CEC2014 functions under the scenarios of small computational resources available for population re-evaluation.

The remainder of this paper is organized as follows. Section 2 reviews the existing research of $\mathrm{mDE}$ algorithms. Section 3 proposes our VB-mDE algorithm. Section 4 evaluates our proposed VB-mDE algorithm with comprehensive simulation results and analysis. Section 5 draws conclusion and gives an outlook on future work.

\section{Literature review}

This section will briefly review the research work of the mDE algorithms. The main methods of mDE include (i) modification of search operators, (ii) local search based method, and (iii) adjustment of parameters or operators, among others.

The first method to develop efficient $\mathrm{mDE}$ algorithms may be modifying the search operators. For example, to address the prematurity problem, a modified DE using smaller population called DESP is developed in [9]. In DESP, the disturbance is introduced to the mutation operator, and an adaptive scheme is also used to adjust the disturbance size. For the purpose of enhancing the population diversity, the random perturbation and modified selection strategies are introduced to the $\mathrm{mDE}$ [10]. It is shown that the two modifications can significantly improve the performance of $\mathrm{mDE}$. However, the $\mathrm{mDE}$ algorithms developed in $[9,10]$ use constant control parameters and were only evaluated in simple test functions. Therefore, it is difficult for them to obtain good performance in complex optimization functions.

The second method may be employing local search technique to design efficient $\mathrm{mDE}$ algorithms. In [11], a mDE algorithm with local search operator, called mDELS, 
is developed and applied for solving large-scale optimization problems. In [12], a mDE algorithm with a directional local search (called $\mu \mathrm{DSDE}$ ) is proposed to solve largescale problems. In $\mu \mathrm{DSDE}$, exploration is realized by reinitializing the worse individuals, while exploitation is performed through mutation, crossover and directional local search. In [11,12], the local search technique increases the exploitation ability of the $\mathrm{mDE}$ algorithms. Meanwhile, it also suffers the risk of local convergence.

The third method may be devising parameter and operator adaptive strategies for $\mathrm{mDE}$ algorithms. In [13], a mDE algorithm with vectorized random mutation factor called MDEVM is proposed. In MDEVM, by randomizing and vectorizing the scale factor, the diversity of the population can be increased, thereby alleviating the problems of premature and stagnation. Later, by employing ensemble mutation and oppositional learning strategies in MDEVM, the ensemble mDE (EMDE) [14] and oppositional ensemble $\mathrm{mDE}$ (OEMDE) [18] are presented, resectively. In the $\mathrm{mDE}$ algorithm$\mathrm{s}[13,14,18]$, the parameter or operator adjustment strategies are devised based on random uniform distribution, and thus the performance is limited. In [6], an adaptive $\mathrm{mDE}$ algorithm called $\mu \mathrm{JADE}$ is proposed. $\mu \mathrm{JADE}$ is developed based on the JADE [19]. In $\mu \mathrm{JADE}$, performance is achieved through implementing a combination of parameter adaptive strategy together with 'current-by-rand-to-pbest' mutation, perturbation strategy and restart strategy. However, the $\mu \mathrm{JADE}$ algorithm has quite high complexity of implementation.

Furthermore, some mDE algorithms are designed for real-world optimization problems. To deal with the image thresholding problem, opposition-based population initialization (OBPI) is embedded into $\mathrm{mDE}$, and a mODE algorithm is proposed in [8]. It is shown that mODE converges faster than $\mathrm{mDE}$ through the OBPI. To solve the optimization problems of topological active net, $\mathrm{mDE}$ with best improvement local search (deBILS) is proposed in [20].

Compact DE (cDE) [21] is a related work to $\mathrm{mDE}$. In $\mathrm{cDE}$, a statistical description of the population is used to evolve the search process and the memory requirement is a population of four individuals.

The existing mDE algorithms may be summarized in Table 1. 
January 2020

Table 1. Summary of existing mDE algorithms

\begin{tabular}{|c|c|c|}
\hline mDE method & mDE Algorithm & Main characteristics \\
\hline \multirow[t]{2}{*}{ Modification of search operators } & DESP [9] & Adaptive disturbance based mutation operator \\
\hline & $\mathrm{mDE}[10]$ & Random perturbation; modified selection strategies \\
\hline \multirow[t]{3}{*}{ Local search based method } & mDELS [11] & Local search \\
\hline & $\mu \mathrm{DSDE}[12]$ & Directional local search; reinitialize the worse individuals \\
\hline & deBILS [20] & Best improvement local search \\
\hline \multirow[t]{4}{*}{ Adjustment of parameters or operators } & MDEVM [13] & Vectorized random scale factor \\
\hline & EMDE [14] & $\begin{array}{l}\text { Vectorized random scale factor; ensemble five mutation opera- } \\
\text { tors }\end{array}$ \\
\hline & OEMDE [18] & $\begin{array}{l}\text { Vectorized random scale factor; ensemble five mutation opera- } \\
\text { tors; opposition-based learning }\end{array}$ \\
\hline & $\mu \mathrm{JADE}[6]$ & $\begin{array}{l}\text { Advanced adaption of scale factor and crossover rate; 'current- } \\
\text { by-rand-to-pbest' mutation; perturbation strategy; restart strat- } \\
\text { egy }\end{array}$ \\
\hline \multirow[t]{2}{*}{ Applications of $\mathrm{mDE}$} & mODE [8] & Image thresholding problem \\
\hline & deBILS [20] & Topological active net optimization problems \\
\hline Virtual population & Compact DE [21] & Virtual population with statistical representation \\
\hline
\end{tabular}

\section{Proposed VB-mDE}

This section proposes a new $\mathrm{mDE}$ algorithm, i.e., vectorized bimodal distribution based micro-DE algorithm (called VB-mDE). Our proposed VB-mDE algorithm can be illustrated by block diagram as in Figure 1.

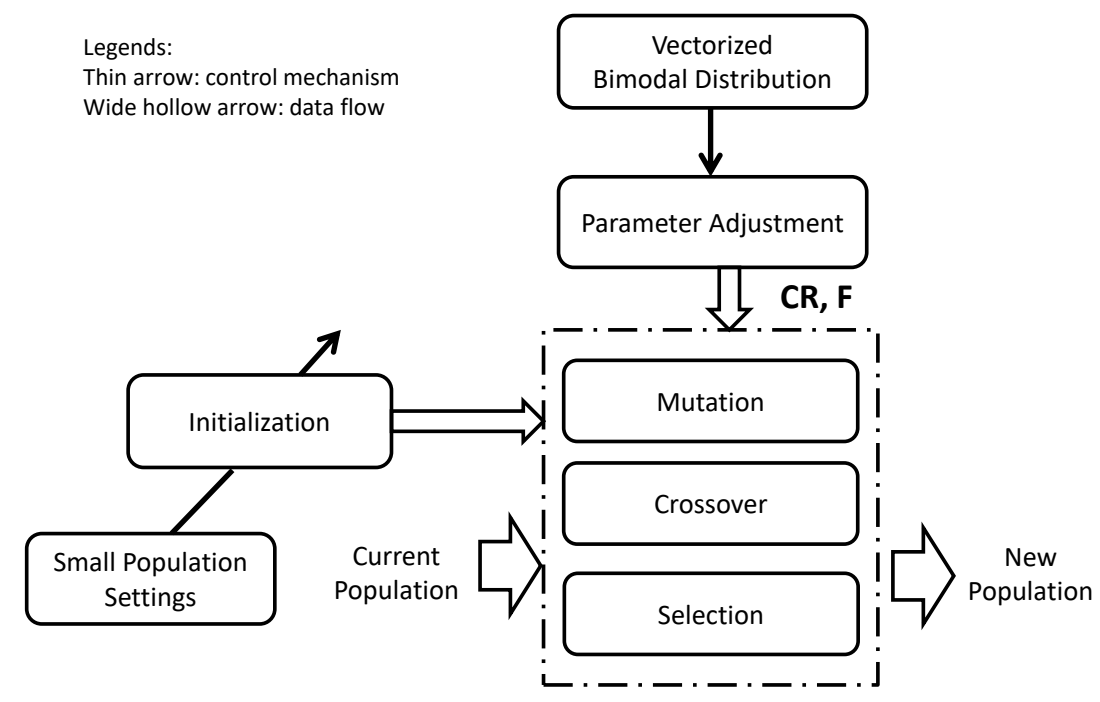

Figure 1. Block diagram of proposed VB-mDE algorithm 


\subsection{Basics of DE}

DE randomly initializes a population of $N p$ individuals in the search space. It is assumed that the dimension of the problem is $D$, the $i$-th individual in the population is:

$$
\boldsymbol{X}_{i}=\left\{x_{i, 1}, x_{i, 2}, \cdots, x_{i, j}, \cdots x_{i, D}\right\}
$$

where $x_{i, j}$ is the $j$-th dimension of the $i$-th individual. Initialization of the population is carried out as follows:

$$
x_{i, j}=x_{j}^{\min }+\left(x_{j}^{\max }-x_{j}^{\min }\right) \times \text { rand }
$$

where $x_{j}^{\max }$ and $x_{j}^{\min }$ denote the upper and lower bounds of the $j$-th dimension across the population, respectively, and rand is a random number within [0,1].

DE works over three phases in order, namely initialization, search and termination. After initialization, DE implements three operators, namely mutation, crossover and selection to generate the offspring of the population in the search, until the termination condition is satisfied.

The mutation operator is firstly applied to generate new offspring. The most commonly used mutation strategies include:

$\mathrm{DE} / \mathrm{rand} / 1$ :

$$
\boldsymbol{V}_{i}=\boldsymbol{X}_{r 1}+F\left(\boldsymbol{X}_{r 2}-\boldsymbol{X}_{r 3}\right)
$$

DE/rand/2:

$$
\boldsymbol{V}_{i}=\boldsymbol{X}_{r 1}+F\left(\boldsymbol{X}_{r 2}-\boldsymbol{X}_{r 3}\right)+F\left(\boldsymbol{X}_{r 4}-\boldsymbol{X}_{r 5}\right)
$$

DE/best/1:

$$
\boldsymbol{V}_{i}=\boldsymbol{X}_{\text {best }}+F\left(\boldsymbol{X}_{r 1}-\boldsymbol{X}_{r 2}\right)
$$

DE/best/2:

$$
\boldsymbol{V}_{i}=\boldsymbol{X}_{\text {best }}+F\left(\boldsymbol{X}_{r 1}-\boldsymbol{X}_{r 2}\right)+F\left(\boldsymbol{X}_{r 3}-\boldsymbol{X}_{r 4}\right)
$$

DE/current-to-best/1:

$$
\boldsymbol{V}_{i}=\boldsymbol{X}_{i}+F\left(\boldsymbol{X}_{\text {best }}-\boldsymbol{X}_{i}\right)+F\left(\boldsymbol{X}_{r 1}-\boldsymbol{X}_{r 2}\right)
$$

where $\boldsymbol{X}_{r 1}, \boldsymbol{X}_{r 2}, \boldsymbol{X}_{r 3}, \boldsymbol{X}_{r 4}$ and $\boldsymbol{X}_{r 5}$ are individuals randomly selected from the population, satisfying $r 1 \neq r 2 \neq r 3 \neq r 4 \neq r 5 \neq i, \boldsymbol{X}_{\text {best }}$ is the best individual in the population, $\boldsymbol{V}_{i}$ is the mutation vector, also called donor vector, and $F$ is the scale factor.

After mutation, the crossover operator is applied between $\boldsymbol{V}_{i}$ and $\boldsymbol{X}_{i}$ to generate the trial vector $\boldsymbol{U}_{i}$, as described below:

$$
U_{i, j}= \begin{cases}V_{i, j} & \text { if rand }<C R \text { or } j=j_{\text {rand }} \\ X_{i, j} & \text { otherwise }\end{cases}
$$

where $U_{i, j}$ is the $j$-th dimension of the $i$-th trial vector $\boldsymbol{U}_{i}, C R$ is the crossover rate, and $j_{\text {rand }}$ is a random integer within $[1, D]$, which ensures that at least one element of $\boldsymbol{U}_{i}$ is from $V_{i}$. 
After crossover, the selection operator is applied between the target vector $\boldsymbol{X}_{i}$ and the trial vector $\boldsymbol{U}_{i}$, as shown below:

$$
\boldsymbol{X}_{i}= \begin{cases}\boldsymbol{U}_{i} & \text { if } f\left(U_{i}\right) \leq f\left(X_{i}\right) \\ \boldsymbol{X}_{i} & \text { otherwise }\end{cases}
$$

where $f\left(\boldsymbol{U}_{i}\right)$ and $f\left(\boldsymbol{X}_{i}\right)$ are the fitness values of $\boldsymbol{U}_{i}$ and $\boldsymbol{X}_{i}$, respectively; and $f\left(\boldsymbol{U}_{i}\right) \leq$ $f\left(\boldsymbol{X}_{i}\right)$ means $\boldsymbol{U}_{i}$ is not worse than $\boldsymbol{X}_{i}$.

\subsection{Vectorized bimodal distribution mechanism for $m D E$}

The bimodal distribution PAM (B-PAM) was proposed in [17], aiming at efficiently combining the global exploration and local exploitation during the searching process. B-PAM has two advantages, i.e., (1) it can be coded very easily in DE; and (2) it is shown that B-PAM obtains consistently high performance [16,17].

In this paper, we will employ B-PAM for the $\mathrm{mDE}$, and integrate it into our VB$\mathrm{mDE}$ algorithm. Furthermore, to enhance the population diversity and reduce the risk of premature convergence, the vectorized mutation strategy [13] is introduced into B-PAM, resulting in a vectorized version of B-PAM, called VB-PAM. To be specific, the bimodal distribution based scale factor in VB-PAM is set as follows:

$$
\begin{aligned}
\boldsymbol{F}_{i} & =\left[F_{\mathrm{i}, 1}, F_{i, 2}, \cdots, F_{i, j}, \cdots, F_{i, D}\right] \quad(i=1,2, \cdots, N p) \\
F_{i, j} & =\left\{\begin{array}{ll}
\operatorname{rand}_{i}(0.65,0.1) & \text { if rand }<0.5 \\
\operatorname{rand}_{i}(1.5,0.1) & \text { otherwise }
\end{array}(j=1,2, \cdots, D)\right.
\end{aligned}
$$

From Eq.(10), it can be seen that the scale factor $\boldsymbol{F}_{i}$ for the $i$-th individual is vectorized. In other words, different values of $F_{i, j}, j=1, \cdots, D$ are used in different dimensions and different individuals [22].

In Eq.(11), $\operatorname{rand}_{i}(\theta, \partial)$ is a random number obeying Cauchy distribution. The range of scale factor $F$ is $[0.1,1.5]^{2}$, the same as in [13]. Moreover, if the value generated by $\operatorname{rand}_{i}(0.65,0.1)$ is smaller than 0.1 , then it will be truncated to 0.1 ; and if the value generated by $\operatorname{rand}_{i}(0.65,0.1)$ is larger than 1.0 , then it will be truncated to 1.0. Likewise, if the value generated by $\operatorname{rand}_{i}(1.5,0.1)$ is smaller than 1.0 , then it will be truncated to 1.0 ; and if the value generated by $\operatorname{rand}_{i}(1.5,0.1)$ is larger than 1.5 , then it will be truncated to 1.5 .

The bimodal distribution based crossover rate is set as follows:

$$
C R_{i}=\left\{\begin{array}{l}
\operatorname{rand}_{i}(0.1,0.1) \quad \text { if rand }<0.5 \\
\operatorname{rand}_{i}(0.95,0.1)
\end{array}\right.
$$

In Eq.(12), the range of cross rate $C R$ is [0,1], which is the same as in [17]. If the value generated by $\operatorname{rand}_{i}(0.1,0.1)$ is smaller than 0 , then it will be truncated to 0 ; and if the value generated by $\operatorname{rand}_{i}(0.95,0.1)$ is larger than 1.0 , then it will be truncated to 1.0 .

In DE, the scale factor $F$ controls the search range of mutation operator. A large value of $F$ is helpful for global exploration, while a small value of $F$ is beneficial for local

\footnotetext{
${ }^{2}$ In $\mathrm{mDE}$, it is very important to keep the population diversity, and therefore the upper bound for scale factor $F$ is set to be a fairly larger value (i.e., 1.5), which is recommended in [13].
} 
exploitation. In Eq.(11), the vectorized scale factor $F$ has 50 percent probability being within $[0.1,1.0]^{D}$, which focuses on local search; and another 50 percent probability being within $[1.0,1.5]^{D}$, which favors the global exploration.

In addition, a large value of $C R$ is helpful for the diversity enhancement, while a small value of $C R$ is helpful for the fast convergence. In Eq.(12), the crossover rate $C R_{i}$ has 50 percent probability being distributed around 0.1 , which puts emphasis on accelerating convergence, and the other 50 percent probability being distributed around 0.95 , which puts emphasis on enhancing the population diversity.

\subsection{Pseudocodes of $V B-m D E$}

By using the VB-PAM and small population, our proposed VB-mDE algorithm can be represented by pseudocodes as shown in Algorithm 1.

The structure of the proposed VB-mDE algorithm would remain unchanged if the mutation strategy rand/1 is substituted with any other mutation strategies, such as rand/2, best/1, best $/ 2$ and current-to-best/1, in which case the VB-mDE algorithm accordingly turns to be a VB-mDE/a/b algorithm. In general, VB-mDE has a very simple structure, just like basic DE, and can be coded and implemented very easily.

\subsection{Difference between $V B-m D E$ and MDEVM}

MDEVM [13] is a recently-developed mDE algorithm, which originally uses the vectorized mutation strategy. Since VB-mDE and MDEVM appear in great similarities, it is worthwhile to highlight the differences between the two algorithms.

The main difference between VB-mDE and MDEVM lies in the parameter adjustment mechanisms. Firstly, MDEVM generates the scale factor $F$ based on a uniform distribution, while VB-mDE utilizes bimodal Cauchy distribution to generate the scale factor $F$. Secondly, MDEVM does not self-adjust the crossover rate $C R$ but only uses a constant value $C R=0.9$. By contrast, $\mathrm{VB}-\mathrm{mDE}$ employs bimodal Cauchy distribution to generate the crossover rate $C R$. 


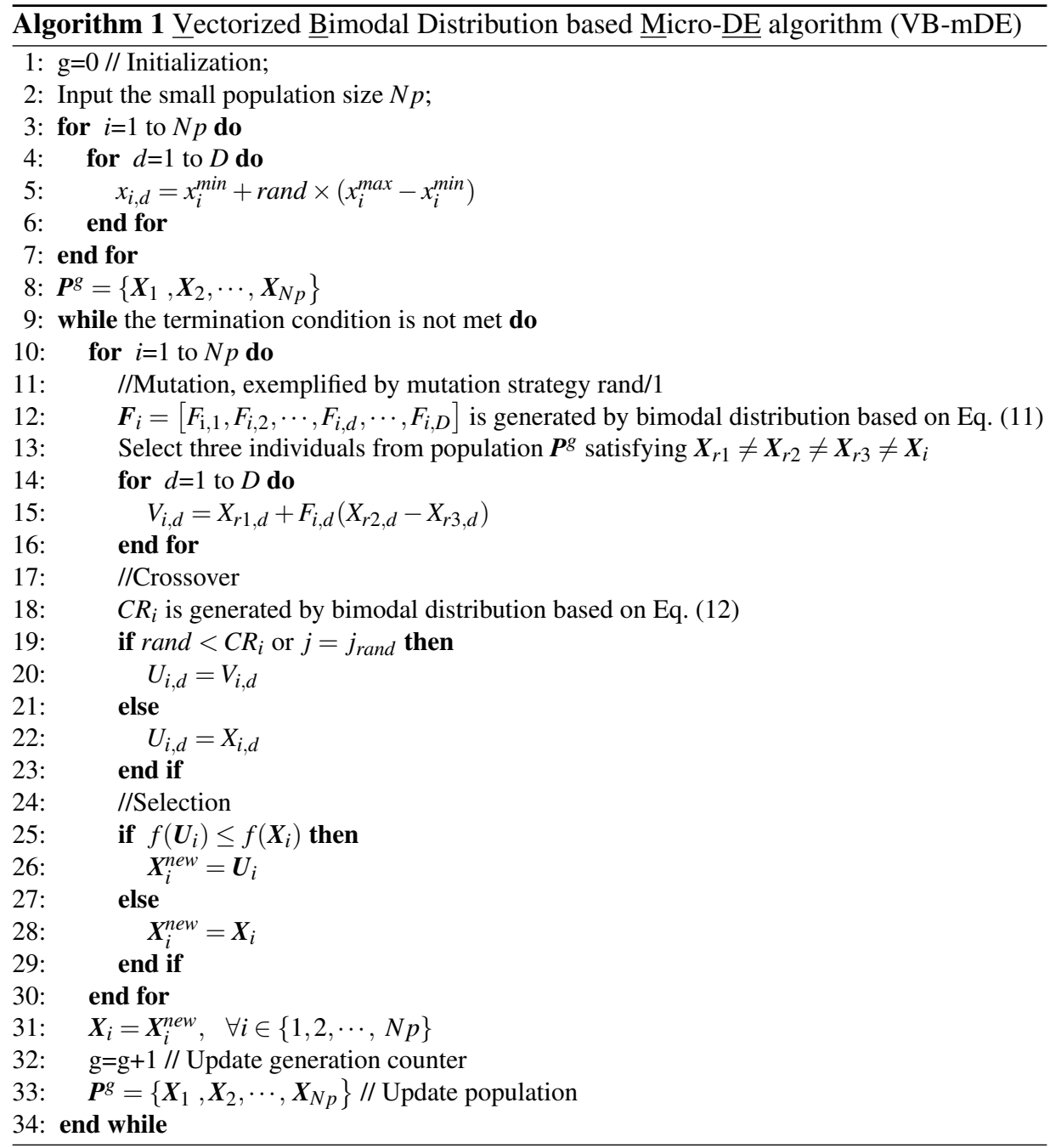

\section{Performance evaluations}

The proposed VB-mDE is compared with the state-of-the-art $\mathrm{mDE}$ and nomal DE algorithms to validate its performance. All the algorithms are tested on 30 benchmark functions from CEC2014 with four different dimensions, i.e., $D=10,30,50$ and 100 [23]. The benchmark functions fall into four groups, i.e., (1) unimodal functions $(\mathrm{F} 1 \sim \mathrm{F} 3)$; (2) simple multimodal functions (F4 F16); (3) hybrid functions (F17 F22); and (4) composition function (F23 F30).

The comparisons are summarized using B-S-W triplets, in which $\mathrm{B}, \mathrm{S}$ and $\mathrm{W}$ represent the numbers of test functions, respectively, on which VB-mDE performs better than, similarly to and worse than its competitor according to the Wilcoxon rank sum test at significant level $\alpha=0.05$. The maximum number of functional evaluations is set to 
$\operatorname{maxFES}=2000 \times D^{3}$, and all the algorithms are implemented 51 times independently. The simulations are conducted in MATLAB2014a and in a PC with Windows 7, Dualcore $3.9 \mathrm{GHz}$ CPU, 4GB RAM.

\subsection{Comparisons between VB-mDE and MDEVM with different small population sizes}

Firstly, we compare VB-mDE and MDEVM to investigate whether the vectorized bimodal distribution based PAM outperforms the vectorized uniform distribution based PAM in the mDEs.

We compare the performances of VB-mDE and MDEVM with different small population sizes. Table 2 shows the comparisons between VB-mDE and MDEVM with small population size $N p \in\{4,5,6,7,8,9,10\}$.

When $N p=4$, VB-mDE outperforms MDEVM on 30, 30 and 24 functions, but loses merely to MDEVM on none, none and 2 functions under the mutation strategies rand/1, best/1 and current-to-best/1, respectively.

When $N p=5$, VB-mDE outperforms MDEVM on 27, 30, 21 and 16 functions, but loses merely to MDEVM on none, none, 1 and none functions under the mutation strategies rand/1, best $/ 1$, best $/ 2$ and current-to-best $/ 1$, respectively.

When $N p=6$, VB-mDE outperforms MDEVM on 24, 21, 23, 20 and 17 functions, but loses merely to MDEVM on 1, 8 , none, 2 and 1 functions under the mutation strategies rand $/ 1$, rand $/ 2$, best $/ 1$, best $/ 2$ and current-to-best $/ 1$, respectively.

When $N p=7,8,9$ and 10, VB-mDE also outperforms MDEVM on most of the test functions under the five mutation strategies rand/1, rand/2, best $/ 1$, best $/ 2$ and current-tobest/1, respectively.

Overall, VB-mDE outperforms MDEVM on 161, 116, 158, 125 and 123 functions, but loses merely to MDEVM on 10, 19, 10, 23 and 11 functions under the mutation strategies rand $/ 1$, rand $/ 2$, best $/ 1$, best $/ 2$ and current-to-best $/ 1$, respectively.

From the comparisons it is clear that VB-mDE performs significantly better than MDEVM on most of the CEC2014 functions with different small population sizes. This validates the effectiveness of the vectorized bimodal distribution based PAM being built in VB-mDE.

\footnotetext{
${ }^{3}$ The recommended $\max F E S$ value for the normal $\mathrm{DE}$ algorithms is $10000 \times D$ in [23]. In this study, the $\mathrm{mDE}$ algorithms use a reduced value $\max F E S=2000 \times D$.
} 
Table 2. Comparisons between VB-mDE and MDEVM with small population sizes $N p \in\{4,5,6,7,8,9,10\}$ for dimension $D=30$

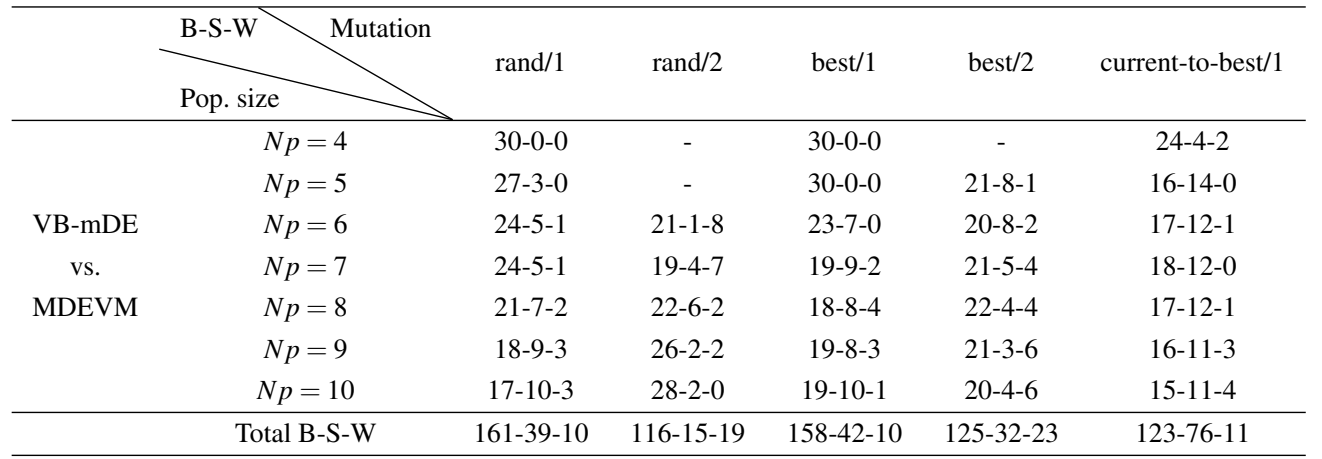

$\mathrm{B}, \mathrm{S}$ and $\mathrm{W}$ represent the numbers of test functions on which VB-mDE performs better than, similarly to, or worse than MDEVM, respectively.

\subsection{Comparisons between $V B-m D E$ and MDEVM with different problem dimensions}

We further compare the performances of VB-mDE and MDEVM with four different problem dimensions. In the comparisons below, the population size for all $\mathrm{mDE}$ algorithms is set as $N p=8$.

Table 3 shows the comparisons between VB-mDE and MDEVM with four different dimensions $D=10,30,50$ and 100 .

When $D=10$, VB-mDE outperforms MDEVM on 21, 25, 27, 24 and 22 functions, but loses to MDEVM only on 3, 1, 2, none and none functions under the mutation strategies rand/1, rand/2, best/1, best/2 and current-to-best/1, respectively.

When $D=30$, VB-mDE outperforms MDEVM on 21, 22, 18, 22 and 17 functions, but loses to MDEVM only on 2, 2, 4, 4 and 1 functions under the mutation strategies rand $/ 1, \mathrm{rand} / 2$, best $/ 1$, best $/ 2$ and current-to-best/1, respectively.

When $D=50$ and 100, VB-mDE also outperforms MDEVM on most of the functions under the mutation strategies rand/1, rand/2, best/1, best/2 and current-to-best/1, respectively.

When considering all four problem dimensions $(D=10,30,50$ and 100), VB-mDE outperforms MDEVM on 84, 93, 85, 87 and 69 functions, but loses to MDEVM only on $12,8,10,16$ and 9 functions under the mutation strategies rand/1, rand/2, best/1, best/2 and current-to-best/1, respectively.

Based on the above analysis, it can be said that VB-mDE largely outperforms MDEVM under any problem dimension and with any mutation strategy. These comparisons further validate the effectiveness of the vectorized bimodal distribution based PAM being built in VB-mDE. 
Table 3. Comparisons between VB-mDE and MDEVM with different problem dimensions

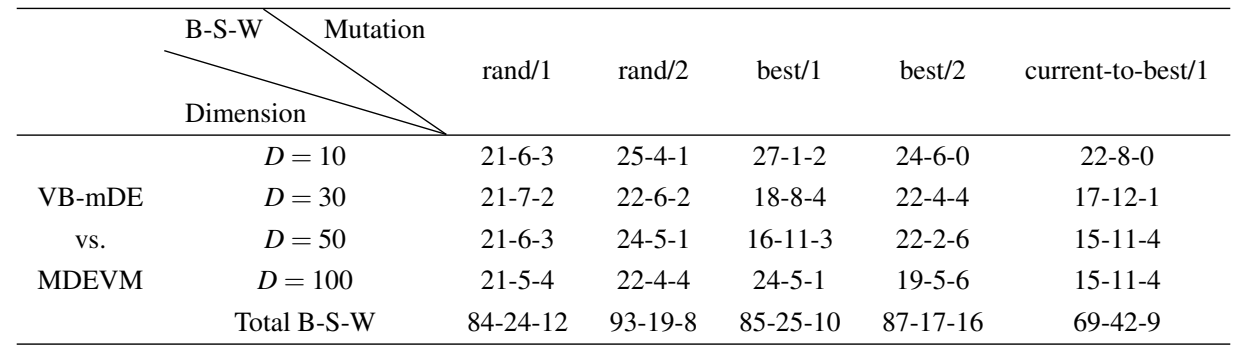

$\mathrm{B}, \mathrm{S}$ and $\mathrm{W}$ represent the numbers of test functions on which VB-mDE performs better than, similarly to, or worse than MDEVM, respectively.

\subsection{Friedman ranks of $V B-m D E$ and $M D E V M$ with different mutation strategies}

To compare the performances of VB-mDE and MDEVM algorithms with five different mutation strategies, Figure 2 plots the Friedman ranks [24] of these algorithms on all the 30 functions .

As can be seen from Figure 2, for all four problem dimensions $D$, VB-mDE/a/b always has a smaller rank than its counterpart MDEVM/a/b.

When $D=10$, VB-mDE/current-to-best/1 achieves the best rank (i.e., 2.47), VB$\mathrm{mDE} /$ best/2 the second (i.e., 3.20), followed by VB-mDE/rand/1 (i.e., 3.50) and others.

When $D=30$, VB-mDE/current-to-best/1 achieves the best rank (i.e., 3.10), VB$\mathrm{mDE} / \mathrm{rand} / 1$ the second (i.e., 3.23), followed by VB-mDE/best/2 (i.e., 3.30) and others.

When $D=50$, VB-mDE/rand/1 achieves the best rank (i.e., 3.10), VB-mDE/currentto-best/1 the second (i.e., 3.47), followed by VB-mDE/best/2 (i.e., 3.53) and others.

When $D=100$, VB-mDE/current-to-best/1 achieves the best rank (i.e., 3.00), VB$\mathrm{mDE} / \mathrm{rand} / 1$ the second (i.e., 3.20), followed by VB-mDE/best/2 (i.e., 3.83) and others.

From the analysis of Friedman test ranks, it is clear that VB-mDE/rand/1 and VB$\mathrm{mDE} /$ current-to-best/1 achieve the overall best performance among the ten $\mathrm{mDE}$ algorithms. Thus, in the following sections, VB-mDE/rand/1 and VB-mDE/current-to-best/1 will be selected for further comparison. 


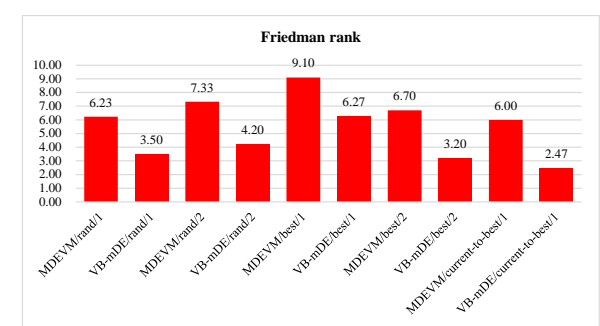

(a) $\mathrm{D}=10$

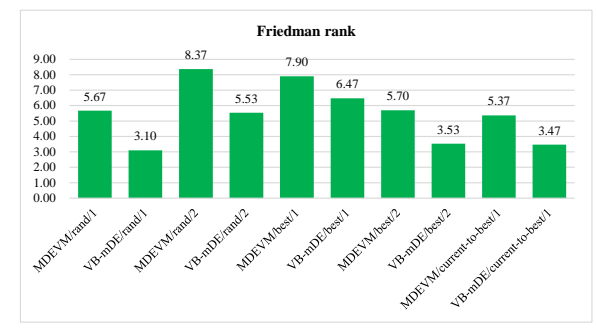

(c) $\mathrm{D}=50$

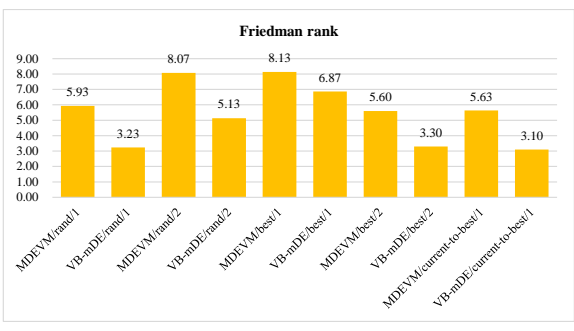

(b) $\mathrm{D}=30$

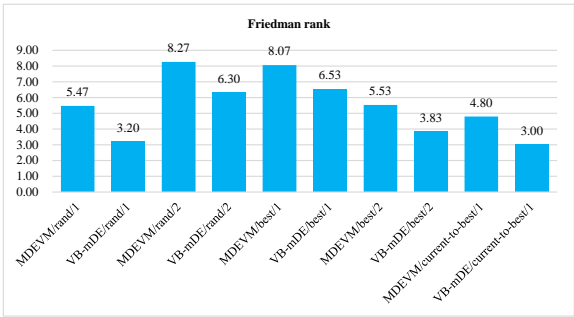

(d) $\mathrm{D}=100$

Figure 2. Friedman ranks of VB-mDE and MDEVM algorithms

\subsection{Convergence comparison between $V B-m D E$ and MDEVMM}

Figure 3 plots the convergence graphs of VB-mDE and MDVEM with mutation strategies rand/1 and current-to-best/1 on some typical functions with $D=30$.

As can be seen from Figure 3, VB-mDE/a/b has relatively faster convergence speed than $\mathrm{MDEVM} / \mathrm{a} / \mathrm{b}$ on these functions.

\subsection{Comparisons between $V B-m D E$ and other $m D E s$}

The performances of VB-mDE/rand/1 and VB-mDE/current-to-best/1 are further compared with other four mDE algorithms, i.e., DESP [9], EMDE [14], OEMDE [18] and $\mu$ JADE [6]. DESP introduces the disturbance with adaptive step size to differential mutation strategy. EMDE is an improved $\mathrm{mDE}$ with ensemble mutation strategies. OEMDE uses both ensemble mutation strategies and opposition-based learning to enhance its performance. $\mu \mathrm{JADE}$ is a small population version of JADE algorithm with very competitive performance.

Table 4 presents the comparisons between VB-mDE and other mDEs with four different dimensions $(D=10,30,50$ and 100).

When $D=10$, VB-mDE/rand/1 outperforms DESP, EMDE, OEMDE and $\mu$ JADE on 23, 20, 24 and 10 functions, respectively; but loses to them only on 2, 1, none and 12 functions, respectively. VB-mDE/current-to-best/1 outperforms DESP, EMDE, OEMDE and $\mu \mathrm{JADE}$ on 25, 22, 27 and 13 functions, respectively; but loses to them only on 2, 1, none and 15 functions, respectively.

When $D=30, \mathrm{VB}-\mathrm{mDE} / \mathrm{rand} / 1$ outperforms DESP, EMDE, OEMDE and $\mu \mathrm{JADE}$ on 23, 20, 25 and 12 functions, respectively; but loses to them only on 2, 2, 1 and 9 functions, respectively. VB-mDE/current-to-best/1 outperforms DESP, EMDE, OEMDE and $\mu \mathrm{JADE}$ on 25, 19, 27 and 13 functions, respectively; but loses to them only on 4, 2, 1 and 7 functions, respectively. 

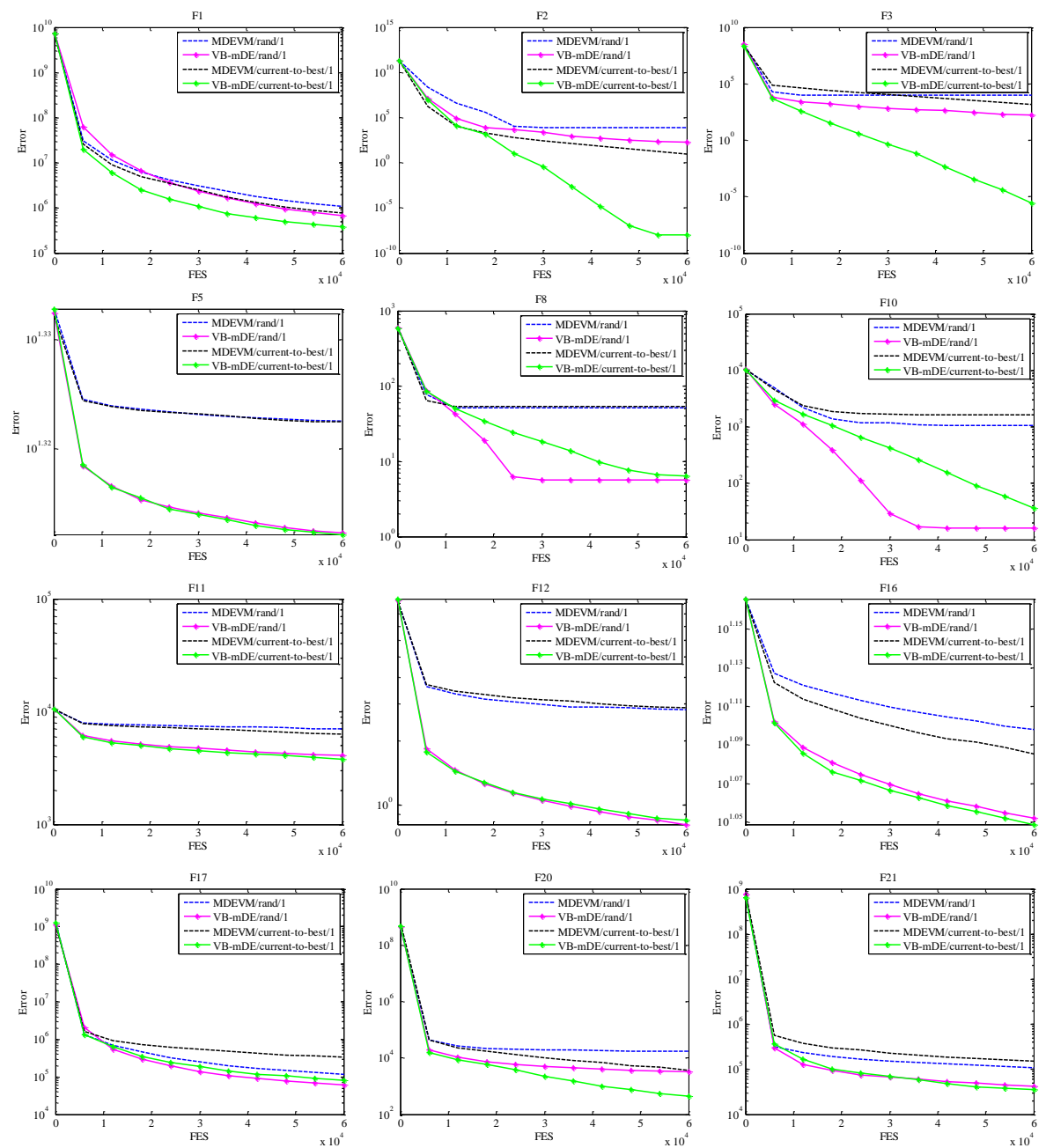

Figure 3. Convergence graphs of VB-mDE and MDEVM algorithms

When $D=50, \mathrm{VB}-\mathrm{mDE} / \mathrm{rand} / 1$ outperforms DESP, EMDE, OEMDE and $\mu$ JADE on 23, 17, 25 and 17 functions, respectively; but loses to them only on 2, 3, 2 and 3 functions, respectively. VB-mDE/current-to-best/1 outperforms DESP, EMDE, OEMDE and $\mu \mathrm{JADE}$ on 23, 17, 22 and 15 functions, respectively; but loses to them only on 2, 5, 1 and 10 functions, respectively.

When $D=100$, VB-mDE/rand/1 outperforms DESP, EMDE, OEMDE and $\mu$ JADE on 20,19, 24 and 15 functions, respectively; but loses to them only on 5, 4, 2 and 8 functions, respectively. VB-mDE/current-to-best/1 outperforms DESP, EMDE, OEMDE and $\mu \mathrm{JADE}$ on 23, 24, 26 and 18 functions, respectively; but loses to them only on 3, 1, 2 and 9 functions, respectively.

When considering all four problem dimension ( $D=10,30,50$ and 100), VB$\mathrm{mDE} / \mathrm{rand} / 1$ outperforms DESP, EMDE, OEMDE and $\mu \mathrm{JADE}$ on 89, 76, 98 and 54 func- 
tions, respectively; but loses to them only on $11,10,5$ and 32 functions, respectively. VB-mDE/current-to-best/1 outperforms DESP, EMDE, OEMDE and $\mu \mathrm{JADE}$ on 96, 82, 102 and 59 functions, respectively; but loses to them only on 11, 9, 4 and 41 functions, respectively.

In summary, based on the above analysis, it is clear that VB-mDE largely exhibit$\mathrm{s}$ better performance than DESP, EMDE and OEMDE with four different dimension$\mathrm{s}(D=10,30,50$ and 100). Compared with $\mu \mathrm{JADE}$, when the dimension is small (i.e., $D=10)$, VB-mDE is slightly worse than $\mu$ JADE; when the dimension increases, VB$\mathrm{mDE}$ exhibits better performance than $\mu \mathrm{JADE}$.

Table 4. Comparisons between VB-mDE and other mDEs with different problem dimensions

\begin{tabular}{llllll}
\hline & B-S-W & & & \\
& Algorithm & DESP & EMDE & OEMDE & $\mu$ JADE \\
\hline$D=10$ & VB-mDE/rand/1 & & & \\
& VB-mDE/current-to-best/1 & $25-3-2$ & $22-7-1$ & $27-3-0$ & $13-2-15$ \\
\hline \multirow{2}{*}{$D=30$} & VB-mDE/rand/1 & $23-5-2$ & $20-8-2$ & $25-4-1$ & $12-9-9$ \\
& VB-mDE/current-to-best/1 & $25-1-4$ & $19-9-2$ & $27-2-1$ & $13-10-7$ \\
\hline \multirow{2}{*}{$D=50$} & VB-mDE/rand/1 & $23-5-2$ & $17-10-3$ & $25-3-2$ & $17-10-3$ \\
& VB-mDE/current-to-best/1 & $23-5-2$ & $17-8-5$ & $22-7-1$ & $15-5-10$ \\
\hline \multirow{2}{*}{$D=100$} & VB-mDE/rand/1 & $20-5-5$ & $19-7-4$ & $24-4-2$ & $15-7-8$ \\
& VB-mDE/current-to-best/1 & $23-4-3$ & $24-5-1$ & $26-2-2$ & $18-3-9$ \\
\hline \multirow{2}{*}{ Total B-S-W } & VB-mDE/rand/1 & $89-20-11$ & $76-34-10$ & $98-17-5$ & $54-34-32$ \\
& VB-mDE/current-to-best/1 & $96-13-11$ & $82-29-9$ & $102-14-4$ & $59-20-41$ \\
\hline
\end{tabular}

$\mathrm{B}, \mathrm{S}$ and $\mathrm{W}$ represent the numbers of test functions on which VB-mDE performs better than, similarly to, or worse than its competitor, respectively.

\subsection{Comparisons between $V B-m D E$ and normal DEs}

The performances of VB-mDE/rand/1 and VB-mDE/current-to-best/1 are further compared with three normal DEs, namely CoBiDE [17], SaDE [25] and JADE [19]. The normal DEs are implemented with small population size, i.e., $\operatorname{CoBiDE}(N p=8), \operatorname{SaDE}$ $(N p=8)$, JADE $(N p=8)$, and also with normal population size, i.e., $\operatorname{CoBiDE}(N p=60)$, $\operatorname{SaDE}(N p=50)$ and JADE $(N p=50)$.

Table 5 presents the comparisons between VB-mDE and DEs with four different dimensions $(D=10,30,50$ and 100).

When $D=10,30,50$ and 100, VB-mDE/rand/1 and VB-mDE/current-to-best/1 perform better than $\operatorname{CoBiDE}(N p=8), \operatorname{SaDE}(N p=8)$ and JADE $(N p=8)$. However, VB$\mathrm{mDE} / \mathrm{rand} / 1$ and VB-mDE/current-to-best/1 perform similarly to or worse than CoBiDE $(N p=60), \operatorname{SaDE}(N p=50)$ and JADE $(N p=50)$. These make sense as $\mathrm{mDE}$ is designed to work on small population size whereas normal DE works on normal population size.

When considering all four problem dimensions $(D=10,30,50$ and 100), VB$\mathrm{mDE} / \mathrm{rand} / 1$ outperforms CoBiDE $(N p=8), \operatorname{SaDE}(N p=8), \operatorname{JADE}(N p=8), \operatorname{CoBiDE}$ $(N p=60), \operatorname{SaDE}(N p=50)$ and JADE $(N p=50)$ on $70,103,74,53,41$ and 10 functions, respectively; but loses to them on $24,12,30,49,52$ and 94 functions, respectively. Likewise, VB-mDE/current-to-best/1 outperforms CoBiDE $(N p=8), \operatorname{SaDE}(N p=8)$, 
$\operatorname{JADE}(N p=8), \operatorname{CoBiDE}(N p=60), \operatorname{SaDE}(N p=50)$ and $\operatorname{JADE}(N p=50)$ on 74,102 , $68,58,45$ and 10 functions, respectively; but loses to them on 20, 9, 23, 47, 52 and 91 functions, respectively.

Based on the above analysis, it can be seen that VB-mDE generally outperforms normal DEs, if the normal DEs are implemented directly with small population size. This also reinforces the motivation that $\mathrm{mDE}$ algorithms should be elaborately designed, rather than simply implementing normal $\mathrm{DE}$ algorithms with small population size.

It can be seen that VB-mDE generally loses to normal DEs with large population size. This is perceivable because DEs with large population size can maintain better diversity. At the same time, it is also worth noting that DEs with large population size cannot be used for some resource constrained optimization applications.

Table 5. Comparisons between VB-mDE and normal DEs with different problem dimensions

\begin{tabular}{|c|c|c|c|c|c|c|c|}
\hline & B-S-W Algorithm & $\begin{array}{l}\text { CoBiDE } \\
(N p=8)\end{array}$ & $\begin{array}{l}\mathrm{SaDE} \\
(N p=8)\end{array}$ & $\begin{array}{l}\text { JADE } \\
(N p=8)\end{array}$ & $\begin{array}{l}\mathrm{CoBiDE} \\
(N p=60)\end{array}$ & $\begin{array}{l}\mathrm{SaDE} \\
(N p=50)\end{array}$ & $\begin{array}{l}\mathrm{JADE} \\
(N p=50)\end{array}$ \\
\hline & Algorithm & & & & & & \\
\hline \multirow[t]{2}{*}{$D=10$} & VB-mDE/rand/1 & $17-8-5$ & $24-2-4$ & $15-6-9$ & $18-5-7$ & $8-8-14$ & $3-5-22$ \\
\hline & VB-mDE/current-to-best/1 & $21-6-3$ & $25-2-3$ & $16-9-5$ & $20-4-6$ & $11-6-13$ & $4-10-16$ \\
\hline \multirow[t]{2}{*}{$D=30$} & VB-mDE/rand/1 & $21-6-3$ & $27-1-2$ & $17-4-9$ & $13-5-12$ & $11-4-15$ & $2-4-24$ \\
\hline & VB-mDE/current-to-best/1 & $23-5-2$ & $26-3-1$ & $21-5-4$ & $15-4-11$ & $11-6-13$ & $3-3-24$ \\
\hline \multirow[t]{2}{*}{$D=50$} & VB-mDE/rand/1 & $19-6-5$ & $27-1-2$ & $17-5-8$ & $11-6-13$ & $11-8-11$ & $3-5-22$ \\
\hline & VB-mDE/current-to-best/1 & $18-9-3$ & $26-3-1$ & $17-9-4$ & $13-4-13$ & $11-9-10$ & $1-3-26$ \\
\hline \multirow[t]{2}{*}{$D=100$} & VB-mDE/rand/1 & $13-6-11$ & $25-1-4$ & $25-1-4$ & $11-2-17$ & $11-7-12$ & $2-2-26$ \\
\hline & VB-mDE/current-to-best/1 & $12-6-12$ & $25-1-4$ & $14-6-10$ & $10-3-17$ & $12-2-16$ & $2-3-25$ \\
\hline \multirow[t]{2}{*}{ Total B-S-W } & VB-mDE/rand/1 & $70-26-24$ & $103-5-12$ & $74-16-30$ & $53-18-49$ & $41-27-52$ & $10-16-94$ \\
\hline & VB-mDE/current-to-best/1 & $74-26-20$ & $102-9-9$ & $68-29-23$ & $58-15-47$ & $45-23-52$ & $10-19-91$ \\
\hline
\end{tabular}

$\mathrm{B}, \mathrm{S}$ and $\mathrm{W}$ represent the numbers of test functions on which VB-mDE performs better than, similarly to, or worse than normal DE, respectively.

\section{Conclusions}

In this paper, a novel bimodal distribution based micro-DE (VB-mDE) has been developed. In our proposed VB-mDE, the vectorized bimodal distribution mechanism is employed to adjust the control parameters. Specifically, the scale factor $F$ and cross rate $C R$ are adjusted by bimodal Cauchy distribution, and the scale factor $F$ is further vectorized. In this way, our proposed VB-mDE can simultaneously conciliate global exploration and local exploitation more efficiently in the $\mathrm{mDE}$.

Comprehensive experiments have been carried out to compare the proposed VB$\mathrm{mDE}$ with the state-of-the-art mDEs and normal DEs using the CEC2014 benchmark functions. Firstly, it is observed that our proposed VB-mDE outperforms the state-of-theart mDEs (including MDEVM, DESP, EMDE, OEMDE and $\mu \mathrm{JADE}$ ) on most functions. This demonstrates the effectiveness of vectorized bimodal distribution mechanism in VB-mDE. Secondly, our proposed VB-mDE outperforms the normal DEs (including CoBiDE, SaDE and JADE), when the normal DEs are implemented directly with small 
January 2020

population size. Compared with DEs with large population size, VB-mDE is defeated in the competition.

There are several aspects worth exploring in the future. Firstly, it is worthwhile to look into other parameter adjustment mechanism to further improve the performance of mDEs. Secondly, this paper only considers the parameter adaptive mechanism for mDE. However, actually, multi-strategy adaptive mechanism may be useful for mDEs as well. Finally, mDEs may be extended to other types of problems, such as constrained, dynamic, multi-objective and real-world problems. 


\section{Appendix 1}

Table A1. Mean error and standard deviation of VB-mDE and MDEVM $(N p=8, D=30)$

\begin{tabular}{|c|c|c|c|c|c|c|c|c|c|}
\hline & VB-mDE/rand/1 & MDEVM/rand/1 & & VB-mDE/best/1 & MDEVM/best/1 & & VB-mDE/cur2best/1 & MDEVM/cur2best/1 & \\
\hline F01 & $\begin{array}{c}6.77 \mathrm{E}+05 \\
(4.67 \mathrm{E}+05)\end{array}$ & $\begin{array}{c}1.07 \mathrm{E}+06 \\
(8.54 \mathrm{E}+05)\end{array}$ & + & $\begin{array}{c}2.17 \mathrm{E}+06 \\
(4.45 \mathrm{E}+06)\end{array}$ & $\begin{array}{c}1.89 \mathrm{E}+06 \\
(1.13 \mathrm{E}+06)\end{array}$ & - & $\begin{array}{c}3.85 \mathrm{E}+05 \\
(3.05 \mathrm{E}+05)\end{array}$ & $\begin{array}{c}7.72 \mathrm{E}+05 \\
(1.53 \mathrm{E}+06)\end{array}$ & + \\
\hline F02 & $\begin{array}{c}1.99 \mathrm{E}+02 \\
(8.30 \mathrm{E}+02)\end{array}$ & $\begin{array}{c}8.09 \mathrm{E}+03 \\
(8.83 \mathrm{E}+03)\end{array}$ & + & $\begin{array}{c}4.96 \mathrm{E}+07 \\
(1.91 \mathrm{E}+08)\end{array}$ & $\begin{array}{c}1.68 \mathrm{E}+04 \\
(2.42 \mathrm{E}+04)\end{array}$ & - & $\begin{array}{c}0.00 \mathrm{E}+00 \\
(0.00 \mathrm{E}+00)\end{array}$ & $\begin{array}{c}8.80 \mathrm{E}+00 \\
(1.39 \mathrm{E}+01)\end{array}$ & + \\
\hline F03 & $\begin{array}{c}1.59 \mathrm{E}+02 \\
(4.92 \mathrm{E}+02) \\
\end{array}$ & $\begin{array}{c}9.33 \mathrm{E}+03 \\
(8.92 \mathrm{E}+03) \\
\end{array}$ & + & $\begin{array}{c}2.12 \mathrm{E}+03 \\
(4.13 \mathrm{E}+03) \\
\end{array}$ & $\begin{array}{c}2.03 \mathrm{E}+04 \\
(1.80 \mathrm{E}+04) \\
\end{array}$ & + & $\begin{array}{c}2.74 \mathrm{E}-06 \\
(8.75 \mathrm{E}-06) \\
\end{array}$ & $\begin{array}{c}1.50 \mathrm{E}+03 \\
(2.44 \mathrm{E}+03) \\
\end{array}$ & + \\
\hline F04 & $\begin{array}{c}7.38 \mathrm{E}+01 \\
(4.61 \mathrm{E}+01)\end{array}$ & $\begin{array}{c}7.35 \mathrm{E}+01 \\
(4.83 \mathrm{E}+01)\end{array}$ & $=$ & $\begin{array}{c}8.26 \mathrm{E}+01 \\
(4.49 \mathrm{E}+01)\end{array}$ & $\begin{array}{c}9.78 \mathrm{E}+01 \\
(3.56 \mathrm{E}+01)\end{array}$ & $=$ & $\begin{array}{c}5.63 \mathrm{E}+01 \\
(4.34 \mathrm{E}+01)\end{array}$ & $\begin{array}{c}4.79 \mathrm{E}+01 \\
(3.60 \mathrm{E}+01)\end{array}$ & $=$ \\
\hline F05 & $\begin{array}{c}2.05 \mathrm{E}+01 \\
(5.74 \mathrm{E}-02)\end{array}$ & $\begin{array}{c}2.10 \mathrm{E}+01 \\
(5.03 \mathrm{E}-02)\end{array}$ & + & $\begin{array}{c}2.05 \mathrm{E}+01 \\
(6.37 \mathrm{E}-02)\end{array}$ & $\begin{array}{c}2.10 \mathrm{E}+01 \\
(5.04 \mathrm{E}-02)\end{array}$ & + & $\begin{array}{c}2.05 \mathrm{E}+01 \\
(5.13 \mathrm{E}-02)\end{array}$ & $\begin{array}{c}2.10 \mathrm{E}+01 \\
(4.78 \mathrm{E}-02)\end{array}$ & + \\
\hline F06 & $\begin{array}{c}1.83 \mathrm{E}+01 \\
(2.86 \mathrm{E}+00)\end{array}$ & $\begin{array}{c}1.30 \mathrm{E}+01 \\
(3.31 \mathrm{E}+00)\end{array}$ & - & $\begin{array}{c}1.96 \mathrm{E}+01 \\
(3.02 \mathrm{E}+00)\end{array}$ & $\begin{array}{c}2.66 \mathrm{E}+01 \\
(3.73 \mathrm{E}+00)\end{array}$ & + & $\begin{array}{c}1.29 \mathrm{E}+01 \\
(4.23 \mathrm{E}+00)\end{array}$ & $\begin{array}{c}1.48 \mathrm{E}+01 \\
(4.20 \mathrm{E}+00)\end{array}$ & $=$ \\
\hline F07 & $\begin{array}{c}1.86 \mathrm{E}-02 \\
(5.24 \mathrm{E}-02)\end{array}$ & $\begin{array}{c}7.13 \mathrm{E}-02 \\
(2.20 \mathrm{E}-01)\end{array}$ & + & $\begin{array}{c}4.36 \mathrm{E}-01 \\
(9.91 \mathrm{E}-01)\end{array}$ & $\begin{array}{c}7.76 \mathrm{E}-01 \\
(3.39 \mathrm{E}+00)\end{array}$ & $=$ & $\begin{array}{c}4.62 \mathrm{E}-02 \\
(6.71 \mathrm{E}-02)\end{array}$ & $\begin{array}{c}4.94 \mathrm{E}-02 \\
(8.62 \mathrm{E}-02)\end{array}$ & $=$ \\
\hline F08 & $\begin{array}{c}5.60 \mathrm{E}+00 \\
(4.02 \mathrm{E}+00)\end{array}$ & $\begin{array}{c}5.13 \mathrm{E}+01 \\
(1.52 \mathrm{E}+01)\end{array}$ & + & $\begin{array}{c}4.75 \mathrm{E}+01 \\
(2.07 \mathrm{E}+01)\end{array}$ & $\begin{array}{c}1.06 \mathrm{E}+02 \\
(3.23 \mathrm{E}+01)\end{array}$ & + & $\begin{array}{c}6.43 \mathrm{E}+00 \\
(6.01 \mathrm{E}+00)\end{array}$ & $\begin{array}{c}5.35 \mathrm{E}+01 \\
(1.54 \mathrm{E}+01)\end{array}$ & + \\
\hline F09 & $\begin{array}{c}1.13 \mathrm{E}+02 \\
(1.21 \mathrm{E}+01)\end{array}$ & $\begin{array}{c}6.06 \mathrm{E}+01 \\
(2.76 \mathrm{E}+01)\end{array}$ & - & $\begin{array}{c}9.59 \mathrm{E}+01 \\
(2.06 \mathrm{E}+01)\end{array}$ & $\begin{array}{c}1.30 \mathrm{E}+02 \\
(3.60 \mathrm{E}+01)\end{array}$ & + & $\begin{array}{c}9.22 \mathrm{E}+01 \\
(1.38 \mathrm{E}+01)\end{array}$ & $\begin{array}{c}7.10 \mathrm{E}+01 \\
(1.58 \mathrm{E}+01)\end{array}$ & - \\
\hline F10 & $\begin{array}{c}1.59 \mathrm{E}+01 \\
(3.24 \mathrm{E}+01)\end{array}$ & $\begin{array}{c}1.06 \mathrm{E}+03 \\
(4.29 \mathrm{E}+02)\end{array}$ & + & $\begin{array}{c}2.07 \mathrm{E}+02 \\
(2.10 \mathrm{E}+02)\end{array}$ & $\begin{array}{c}2.46 \mathrm{E}+03 \\
(5.31 \mathrm{E}+02)\end{array}$ & + & $\begin{array}{c}3.62 \mathrm{E}+01 \\
(2.64 \mathrm{E}+01)\end{array}$ & $\begin{array}{c}1.62 \mathrm{E}+03 \\
(6.26 \mathrm{E}+02)\end{array}$ & + \\
\hline F11 & $\begin{array}{c}4.09 \mathrm{E}+03 \\
(3.86 \mathrm{E}+02)\end{array}$ & $\begin{array}{c}7.01 \mathrm{E}+03 \\
(1.21 \mathrm{E}+03)\end{array}$ & + & $\begin{array}{c}3.76 \mathrm{E}+03 \\
(3.99 \mathrm{E}+02)\end{array}$ & $\begin{array}{c}3.44 \mathrm{E}+03 \\
(9.54 \mathrm{E}+02)\end{array}$ & - & $\begin{array}{c}3.80 \mathrm{E}+03 \\
(3.26 \mathrm{E}+02)\end{array}$ & $\begin{array}{c}6.33 \mathrm{E}+03 \\
(1.46 \mathrm{E}+03)\end{array}$ & + \\
\hline F12 & $\begin{array}{c}8.06 \mathrm{E}-01 \\
(1.20 \mathrm{E}-01)\end{array}$ & $\begin{array}{c}2.82 \mathrm{E}+00 \\
(3.47 \mathrm{E}-01)\end{array}$ & + & $\begin{array}{c}8.24 \mathrm{E}-01 \\
(1.28 \mathrm{E}-01)\end{array}$ & $\begin{array}{c}2.47 \mathrm{E}+00 \\
(1.02 \mathrm{E}+00)\end{array}$ & + & $\begin{array}{c}8.44 \mathrm{E}-01 \\
(1.34 \mathrm{E}-01)\end{array}$ & $\begin{array}{c}2.88 \mathrm{E}+00 \\
(3.38 \mathrm{E}-01)\end{array}$ & + \\
\hline F13 & $\begin{array}{c}4.39 \mathrm{E}-01 \\
(8.12 \mathrm{E}-02)\end{array}$ & $\begin{array}{c}5.01 \mathrm{E}-01 \\
(1.04 \mathrm{E}-01)\end{array}$ & + & $\begin{array}{c}5.05 \mathrm{E}-01 \\
(1.16 \mathrm{E}-01)\end{array}$ & $\begin{array}{c}5.61 \mathrm{E}-01 \\
(1.57 \mathrm{E}-01)\end{array}$ & $=$ & $\begin{array}{c}4.65 \mathrm{E}-01 \\
(7.42 \mathrm{E}-02)\end{array}$ & $\begin{array}{c}5.00 \mathrm{E}-01 \\
(1.04 \mathrm{E}-01)\end{array}$ & $=$ \\
\hline F14 & $\begin{array}{c}2.90 \mathrm{E}-01 \\
(4.43 \mathrm{E}-02)\end{array}$ & $\begin{array}{c}3.49 \mathrm{E}-01 \\
(1.58 \mathrm{E}-01)\end{array}$ & $=$ & $\begin{array}{c}4.54 \mathrm{E}-01 \\
(7.60 \mathrm{E}-01)\end{array}$ & $\begin{array}{c}4.30 \mathrm{E}-01 \\
(2.71 \mathrm{E}-01)\end{array}$ & $=$ & $\begin{array}{c}2.64 \mathrm{E}-01 \\
(4.73 \mathrm{E}-02)\end{array}$ & $\begin{array}{c}3.48 \mathrm{E}-01 \\
(1.51 \mathrm{E}-01)\end{array}$ & + \\
\hline F15 & $\begin{array}{c}1.16 \mathrm{E}+01 \\
(1.47 \mathrm{E}+00)\end{array}$ & $\begin{array}{c}1.63 \mathrm{E}+01 \\
(1.03 \mathrm{E}+01)\end{array}$ & $=$ & $\begin{array}{c}1.31 \mathrm{E}+02 \\
(3.55 \mathrm{E}+02)\end{array}$ & $\begin{array}{c}3.70 \mathrm{E}+02 \\
(3.74 \mathrm{E}+02)\end{array}$ & + & $\begin{array}{c}1.73 \mathrm{E}+01 \\
(6.90 \mathrm{E}+00)\end{array}$ & $\begin{array}{c}1.64 \mathrm{E}+01 \\
(1.26 \mathrm{E}+01)\end{array}$ & $=$ \\
\hline F16 & $\begin{array}{c}1.13 \mathrm{E}+01 \\
(3.54 \mathrm{E}-01) \\
\end{array}$ & $\begin{array}{c}1.25 \mathrm{E}+01 \\
(7.49 \mathrm{E}-01) \\
\end{array}$ & + & $\begin{array}{c}1.10 \mathrm{E}+01 \\
(4.54 \mathrm{E}-01)\end{array}$ & $\begin{array}{c}1.13 \mathrm{E}+01 \\
(7.85 \mathrm{E}-01) \\
\end{array}$ & + & $\begin{array}{c}1.12 \mathrm{E}+01 \\
(4.35 \mathrm{E}-01)\end{array}$ & $\begin{array}{c}1.22 \mathrm{E}+01 \\
(5.71 \mathrm{E}-01) \\
\end{array}$ & + \\
\hline F17 & $\begin{array}{c}6.04 \mathrm{E}+04 \\
(4.10 \mathrm{E}+04)\end{array}$ & $\begin{array}{c}1.16 \mathrm{E}+05 \\
(6.97 \mathrm{E}+04)\end{array}$ & + & $\begin{array}{c}2.24 \mathrm{E}+05 \\
(4.50 \mathrm{E}+05)\end{array}$ & $\begin{array}{c}3.81 \mathrm{E}+05 \\
(2.32 \mathrm{E}+05)\end{array}$ & + & $\begin{array}{c}7.91 \mathrm{E}+04 \\
(7.19 \mathrm{E}+04)\end{array}$ & $\begin{array}{c}3.38 \mathrm{E}+05 \\
(2.91 \mathrm{E}+05)\end{array}$ & + \\
\hline F18 & $\begin{array}{c}3.31 \mathrm{E}+03 \\
(3.95 \mathrm{E}+03)\end{array}$ & $\begin{array}{c}2.68 \mathrm{E}+03 \\
(3.24 \mathrm{E}+03)\end{array}$ & $=$ & $\begin{array}{c}4.46 \mathrm{E}+06 \\
(2.26 \mathrm{E}+07)\end{array}$ & $\begin{array}{c}4.08 \mathrm{E}+03 \\
(4.34 \mathrm{E}+03)\end{array}$ & $=$ & $\begin{array}{c}1.98 \mathrm{E}+03 \\
(2.22 \mathrm{E}+03)\end{array}$ & $\begin{array}{c}3.65 \mathrm{E}+03 \\
(4.28 \mathrm{E}+03)\end{array}$ & $=$ \\
\hline F19 & $\begin{array}{c}1.02 \mathrm{E}+01 \\
(1.48 \mathrm{E}+01)\end{array}$ & $\begin{array}{c}1.66 \mathrm{E}+01 \\
(2.31 \mathrm{E}+01)\end{array}$ & $=$ & $\begin{array}{c}2.74 \mathrm{E}+01 \\
(4.72 \mathrm{E}+01)\end{array}$ & $\begin{array}{c}2.72 \mathrm{E}+01 \\
(2.86 \mathrm{E}+01)\end{array}$ & - & $\begin{array}{c}1.18 \mathrm{E}+01 \\
(1.62 \mathrm{E}+01)\end{array}$ & $\begin{array}{c}1.26 \mathrm{E}+01 \\
(1.73 \mathrm{E}+01)\end{array}$ & $=$ \\
\hline F20 & $\begin{array}{c}3.32 \mathrm{E}+03 \\
(4.20 \mathrm{E}+03)\end{array}$ & $\begin{array}{c}1.74 \mathrm{E}+04 \\
(1.17 \mathrm{E}+04)\end{array}$ & + & $\begin{array}{c}6.15 \mathrm{E}+03 \\
(7.08 \mathrm{E}+03)\end{array}$ & $\begin{array}{c}3.70 \mathrm{E}+04 \\
(1.99 \mathrm{E}+04)\end{array}$ & + & $\begin{array}{c}4.38 \mathrm{E}+02 \\
(4.45 \mathrm{E}+02)\end{array}$ & $\begin{array}{c}3.67 \mathrm{E}+03 \\
(3.84 \mathrm{E}+03)\end{array}$ & + \\
\hline F21 & $\begin{array}{c}4.22 \mathrm{E}+04 \\
(4.53 \mathrm{E}+04)\end{array}$ & $\begin{array}{c}1.09 \mathrm{E}+05 \\
(8.50 \mathrm{E}+04) \\
\end{array}$ & + & $\begin{array}{c}8.09 \mathrm{E}+04 \\
(1.00 \mathrm{E}+05) \\
\end{array}$ & $\begin{array}{c}2.97 \mathrm{E}+05 \\
(2.81 \mathrm{E}+05) \\
\end{array}$ & + & $\begin{array}{c}3.60 \mathrm{E}+04 \\
(3.74 \mathrm{E}+04) \\
\end{array}$ & $\begin{array}{c}1.51 \mathrm{E}+05 \\
(1.88 \mathrm{E}+05) \\
\end{array}$ & + \\
\hline F22 & $\begin{array}{c}2.86 \mathrm{E}+02 \\
(1.17 \mathrm{E}+02)\end{array}$ & $\begin{array}{c}3.30 \mathrm{E}+02 \\
(2.18 \mathrm{E}+02)\end{array}$ & $=$ & $\begin{array}{c}4.35 \mathrm{E}+02 \\
(2.22 \mathrm{E}+02)\end{array}$ & $\begin{array}{c}6.17 \mathrm{E}+02 \\
(2.41 \mathrm{E}+02)\end{array}$ & + & $\begin{array}{c}2.61 \mathrm{E}+02 \\
(1.11 \mathrm{E}+02)\end{array}$ & $\begin{array}{c}2.72 \mathrm{E}+02 \\
(1.15 \mathrm{E}+02)\end{array}$ & $=$ \\
\hline F23 & $\begin{array}{c}3.15 \mathrm{E}+02 \\
(6.62 \mathrm{E}-12)\end{array}$ & $\begin{array}{c}3.15 \mathrm{E}+02 \\
(1.11 \mathrm{E}-06)\end{array}$ & + & $\begin{array}{c}3.16 \mathrm{E}+02 \\
(1.01 \mathrm{E}+00)\end{array}$ & $\begin{array}{c}3.15 \mathrm{E}+02 \\
(2.59 \mathrm{E}-01)\end{array}$ & $=$ & $\begin{array}{c}3.15 \mathrm{E}+02 \\
(2.84 \mathrm{E}-11)\end{array}$ & $\begin{array}{l}3.15 \mathrm{E}+02 \\
(6.05 \mathrm{E}-10)\end{array}$ & + \\
\hline F24 & $\begin{array}{c}2.32 \mathrm{E}+02 \\
(6.36 \mathrm{E}+00)\end{array}$ & $\begin{array}{c}2.45 \mathrm{E}+02 \\
(6.27 \mathrm{E}+00)\end{array}$ & + & $\begin{array}{c}2.52 \mathrm{E}+02 \\
(8.18 \mathrm{E}+00)\end{array}$ & $\begin{array}{c}2.59 \mathrm{E}+02 \\
(9.50 \mathrm{E}+00)\end{array}$ & + & $\begin{array}{c}2.43 \mathrm{E}+02 \\
(6.95 \mathrm{E}+00)\end{array}$ & $\begin{array}{c}2.45 \mathrm{E}+02 \\
(8.23 \mathrm{E}+00)\end{array}$ & $=$ \\
\hline F25 & $\begin{array}{c}2.06 \mathrm{E}+02 \\
(1.87 \mathrm{E}+00)\end{array}$ & $\begin{array}{c}2.08 \mathrm{E}+02 \\
(3.38 \mathrm{E}+00)\end{array}$ & + & $\begin{array}{c}2.15 \mathrm{E}+02 \\
(5.96 \mathrm{E}+00)\end{array}$ & $\begin{array}{c}2.18 \mathrm{E}+02 \\
(8.45 \mathrm{E}+00)\end{array}$ & $=$ & $\begin{array}{c}2.09 \mathrm{E}+02 \\
(3.89 \mathrm{E}+00)\end{array}$ & $\begin{array}{c}2.10 \mathrm{E}+02 \\
(4.48 \mathrm{E}+00)\end{array}$ & $=$ \\
\hline F26 & $\begin{array}{c}1.06 \mathrm{E}+02 \\
(2.37 \mathrm{E}+01)\end{array}$ & $\begin{array}{c}1.10 \mathrm{E}+02 \\
(2.99 \mathrm{E}+01)\end{array}$ & + & $\begin{array}{c}1.39 \mathrm{E}+02 \\
(5.60 \mathrm{E}+01)\end{array}$ & $\begin{array}{c}1.54 \mathrm{E}+02 \\
(6.48 \mathrm{E}+01)\end{array}$ & + & $\begin{array}{c}1.36 \mathrm{E}+02 \\
(4.81 \mathrm{E}+01)\end{array}$ & $\begin{array}{c}1.22 \mathrm{E}+02 \\
(4.14 \mathrm{E}+01)\end{array}$ & $=$ \\
\hline F27 & $\begin{array}{c}4.98 \mathrm{E}+02 \\
(1.48 \mathrm{E}+02)\end{array}$ & $\begin{array}{c}6.05 \mathrm{E}+02 \\
(1.29 \mathrm{E}+02)\end{array}$ & + & $\begin{array}{c}7.73 \mathrm{E}+02 \\
(2.16 \mathrm{E}+02)\end{array}$ & $\begin{array}{c}9.21 \mathrm{E}+02 \\
(2.86 \mathrm{E}+02)\end{array}$ & + & $\begin{array}{c}4.92 \mathrm{E}+02 \\
(1.14 \mathrm{E}+02)\end{array}$ & $\begin{array}{c}6.35 \mathrm{E}+02 \\
(1.52 \mathrm{E}+02)\end{array}$ & + \\
\hline F28 & $\begin{array}{c}9.75 \mathrm{E}+02 \\
(5.66 \mathrm{E}+01)\end{array}$ & $\begin{array}{c}1.08 \mathrm{E}+03 \\
(1.65 \mathrm{E}+02)\end{array}$ & + & $\begin{array}{c}1.35 \mathrm{E}+03 \\
(3.15 \mathrm{E}+02)\end{array}$ & $\begin{array}{c}1.99 \mathrm{E}+03 \\
(5.52 \mathrm{E}+02)\end{array}$ & + & $\begin{array}{c}9.84 \mathrm{E}+02 \\
(9.17 \mathrm{E}+01)\end{array}$ & $\begin{array}{c}1.09 \mathrm{E}+03 \\
(1.19 \mathrm{E}+02)\end{array}$ & + \\
\hline F29 & $\begin{array}{c}1.36 \mathrm{E}+03 \\
(3.71 \mathrm{E}+02)\end{array}$ & $\begin{array}{c}1.28 \mathrm{E}+03 \\
(3.27 \mathrm{E}+02)\end{array}$ & $=$ & $\begin{array}{c}2.01 \mathrm{E}+03 \\
(2.66 \mathrm{E}+03)\end{array}$ & $\begin{array}{c}1.57 \mathrm{E}+03 \\
(6.81 \mathrm{E}+02)\end{array}$ & $=$ & $\begin{array}{c}1.17 \mathrm{E}+03 \\
(3.88 \mathrm{E}+02)\end{array}$ & $\begin{array}{c}1.39 \mathrm{E}+03 \\
(4.57 \mathrm{E}+02)\end{array}$ & + \\
\hline F30 & $\begin{array}{c}2.13 \mathrm{E}+03 \\
(7.60 \mathrm{E}+02)\end{array}$ & $\begin{array}{c}2.77 \mathrm{E}+03 \\
(9.04 \mathrm{E}+02)\end{array}$ & + & $\begin{array}{c}3.62 \mathrm{E}+03 \\
(9.64 \mathrm{E}+02)\end{array}$ & $\begin{array}{c}5.04 \mathrm{E}+03 \\
(3.77 \mathrm{E}+03)\end{array}$ & + & $\begin{array}{c}2.49 \mathrm{E}+03 \\
(8.97 \mathrm{E}+02)\end{array}$ & $\begin{array}{c}2.44 \mathrm{E}+03 \\
(1.07 \mathrm{E}+03)\end{array}$ & $=$ \\
\hline B-S-W & & $21-7-2$ & & & $18-8-4$ & & & $17-12-1$ & \\
\hline
\end{tabular}

,$+=$ and - symbolize VB-mDE being better than, similar to, or worse than MDEVM, respectively. 
Table A2. Mean error and standard deviation of VB-mDE and other mDEs $(N p=8, D=30)$

\begin{tabular}{|c|c|c|c|c|c|c|c|c|c|}
\hline & VB-mDE/rand/1 & DESP & & EMDE & & OEMDE & & $\mu \mathrm{JADE}$ & \\
\hline F01 & $\begin{array}{c}6.77 \mathrm{E}+05 \\
(4.67 \mathrm{E}+05)\end{array}$ & $\begin{array}{c}3.20 \mathrm{E}+06 \\
(1.57 \mathrm{E}+06)\end{array}$ & + & $\begin{array}{c}7.12 \mathrm{E}+05 \\
(4.98 \mathrm{E}+05)\end{array}$ & $=$ & $\begin{array}{c}6.61 \mathrm{E}+07 \\
(2.68 \mathrm{E}+08)\end{array}$ & + & $\begin{array}{c}1.08 \mathrm{E}+07 \\
(6.24 \mathrm{E}+06)\end{array}$ & + \\
\hline F02 & $\begin{array}{c}1.99 \mathrm{E}+02 \\
(8.30 \mathrm{E}+02)\end{array}$ & $\begin{array}{c}1.09 \mathrm{E}+04 \\
(8.84 \mathrm{E}+03)\end{array}$ & + & $\begin{array}{c}8.35 \mathrm{E}+03 \\
(7.99 \mathrm{E}+03)\end{array}$ & + & $\begin{array}{c}1.06 \mathrm{E}+04 \\
(9.91 \mathrm{E}+03)\end{array}$ & + & $\begin{array}{c}4.91 \mathrm{E}-10 \\
(3.51 \mathrm{E}-09)\end{array}$ & - \\
\hline F03 & $\begin{array}{c}1.59 \mathrm{E}+02 \\
(4.92 \mathrm{E}+02)\end{array}$ & $\begin{array}{c}7.10 \mathrm{E}+04 \\
(1.89 \mathrm{E}+04)\end{array}$ & + & $\begin{array}{c}8.66 \mathrm{E}+03 \\
(8.20 \mathrm{E}+03)\end{array}$ & + & $\begin{array}{c}6.02 \mathrm{E}+05 \\
(3.54 \mathrm{E}+06)\end{array}$ & + & $\begin{array}{c}6.50 \mathrm{E}-04 \\
(2.63 \mathrm{E}-03)\end{array}$ & - \\
\hline F04 & $\begin{array}{c}7.38 \mathrm{E}+01 \\
(4.61 \mathrm{E}+01)\end{array}$ & $\begin{array}{c}1.25 \mathrm{E}+02 \\
(3.82 \mathrm{E}+01)\end{array}$ & + & $\begin{array}{c}6.08 \mathrm{E}+01 \\
(3.45 \mathrm{E}+01)\end{array}$ & $=$ & $\begin{array}{c}8.34 \mathrm{E}+01 \\
(4.14 \mathrm{E}+01)\end{array}$ & $=$ & $\begin{array}{c}5.88 \mathrm{E}+01 \\
(4.48 \mathrm{E}+01)\end{array}$ & - \\
\hline F05 & $\begin{array}{c}2.05 \mathrm{E}+01 \\
(5.74 \mathrm{E}-02)\end{array}$ & $\begin{array}{c}2.03 \mathrm{E}+01 \\
(4.17 \mathrm{E}-01)\end{array}$ & - & $\begin{array}{c}2.10 \mathrm{E}+01 \\
(5.18 \mathrm{E}-02)\end{array}$ & + & $\begin{array}{c}2.10 \mathrm{E}+01 \\
(2.02 \mathrm{E}-01)\end{array}$ & + & $\begin{array}{c}2.04 \mathrm{E}+01 \\
(1.84 \mathrm{E}-01)\end{array}$ & - \\
\hline F06 & $\begin{array}{c}1.83 \mathrm{E}+01 \\
(2.86 \mathrm{E}+00)\end{array}$ & $\begin{array}{c}2.44 \mathrm{E}+01 \\
(3.36 \mathrm{E}+00)\end{array}$ & + & $\begin{array}{c}1.61 \mathrm{E}+01 \\
(3.48 \mathrm{E}+00)\end{array}$ & - & $\begin{array}{c}2.25 \mathrm{E}+01 \\
(9.89 \mathrm{E}+00)\end{array}$ & $=$ & $\begin{array}{c}2.62 \mathrm{E}+01 \\
(1.71 \mathrm{E}+00)\end{array}$ & + \\
\hline F07 & $\begin{array}{c}1.86 \mathrm{E}-02 \\
(5.24 \mathrm{E}-02)\end{array}$ & $\begin{array}{c}1.27 \mathrm{E}-02 \\
(1.59 \mathrm{E}-02)\end{array}$ & $=$ & $\begin{array}{c}2.23 \mathrm{E}-01 \\
(1.16 \mathrm{E}+00)\end{array}$ & + & $\begin{array}{c}1.00 \mathrm{E}-01 \\
(1.65 \mathrm{E}-01)\end{array}$ & + & $\begin{array}{c}6.03 \mathrm{E}-03 \\
(1.19 \mathrm{E}-02)\end{array}$ & $=$ \\
\hline F08 & $\begin{array}{c}5.60 \mathrm{E}+00 \\
(4.02 \mathrm{E}+00)\end{array}$ & $\begin{array}{c}1.07 \mathrm{E}+02 \\
(2.43 \mathrm{E}+01)\end{array}$ & + & $\begin{array}{c}6.36 \mathrm{E}+01 \\
(1.62 \mathrm{E}+01)\end{array}$ & + & $\begin{array}{c}6.22 \mathrm{E}+01 \\
(1.87 \mathrm{E}+01)\end{array}$ & + & $\begin{array}{c}3.31 \mathrm{E}+01 \\
(8.87 \mathrm{E}+00)\end{array}$ & + \\
\hline F09 & $\begin{array}{c}1.13 \mathrm{E}+02 \\
(1.21 \mathrm{E}+01)\end{array}$ & $\begin{array}{c}1.34 \mathrm{E}+02 \\
(3.52 \mathrm{E}+01)\end{array}$ & + & $\begin{array}{c}7.66 \mathrm{E}+01 \\
(2.52 \mathrm{E}+01)\end{array}$ & - & $\begin{array}{c}8.54 \mathrm{E}+01 \\
(2.48 \mathrm{E}+01)\end{array}$ & - & $\begin{array}{c}1.62 \mathrm{E}+02 \\
(1.87 \mathrm{E}+01)\end{array}$ & + \\
\hline F10 & $\begin{array}{c}1.59 \mathrm{E}+01 \\
(3.24 \mathrm{E}+01)\end{array}$ & $\begin{array}{c}2.67 \mathrm{E}+03 \\
(7.16 \mathrm{E}+02)\end{array}$ & + & $\begin{array}{c}1.38 \mathrm{E}+03 \\
(4.91 \mathrm{E}+02)\end{array}$ & + & $\begin{array}{c}3.56 \mathrm{E}+03 \\
(2.06 \mathrm{E}+03)\end{array}$ & + & $\begin{array}{c}1.05 \mathrm{E}+03 \\
(3.79 \mathrm{E}+02)\end{array}$ & + \\
\hline F11 & $\begin{array}{c}4.09 \mathrm{E}+03 \\
(3.86 \mathrm{E}+02)\end{array}$ & $\begin{array}{c}3.38 \mathrm{E}+03 \\
(8.16 \mathrm{E}+02)\end{array}$ & - & $\begin{array}{c}5.84 \mathrm{E}+03 \\
(2.23 \mathrm{E}+03)\end{array}$ & + & $\begin{array}{c}6.48 \mathrm{E}+03 \\
(1.55 \mathrm{E}+03)\end{array}$ & + & $\begin{array}{c}5.32 \mathrm{E}+03 \\
(7.49 \mathrm{E}+02)\end{array}$ & + \\
\hline F12 & $\begin{array}{c}8.06 \mathrm{E}-01 \\
(1.20 \mathrm{E}-01)\end{array}$ & $\begin{array}{c}1.05 \mathrm{E}+00 \\
(4.36 \mathrm{E}-01)\end{array}$ & + & $\begin{array}{c}2.83 \mathrm{E}+00 \\
(3.49 \mathrm{E}-01)\end{array}$ & + & $\begin{array}{c}2.15 \mathrm{E}+00 \\
(1.23 \mathrm{E}+00)\end{array}$ & + & $\begin{array}{c}8.66 \mathrm{E}-01 \\
(5.46 \mathrm{E}-01)\end{array}$ & $=$ \\
\hline F13 & $\begin{array}{c}4.39 \mathrm{E}-01 \\
(8.12 \mathrm{E}-02)\end{array}$ & $\begin{array}{c}4.28 \mathrm{E}-01 \\
(9.84 \mathrm{E}-02)\end{array}$ & $=$ & $\begin{array}{c}4.90 \mathrm{E}-01 \\
(9.74 \mathrm{E}-02)\end{array}$ & + & $\begin{array}{c}5.25 \mathrm{E}-01 \\
(1.11 \mathrm{E}-01)\end{array}$ & + & $\begin{array}{c}4.57 \mathrm{E}-01 \\
(6.62 \mathrm{E}-02)\end{array}$ & $=$ \\
\hline F14 & $\begin{array}{c}2.90 \mathrm{E}-01 \\
(4.43 \mathrm{E}-02)\end{array}$ & $\begin{array}{c}2.88 \mathrm{E}-01 \\
(7.50 \mathrm{E}-02)\end{array}$ & $=$ & $\begin{array}{c}3.58 \mathrm{E}-01 \\
(1.70 \mathrm{E}-01)\end{array}$ & $=$ & $\begin{array}{c}3.49 \mathrm{E}-01 \\
(1.35 \mathrm{E}-01)\end{array}$ & + & $\begin{array}{c}3.40 \mathrm{E}-01 \\
(1.57 \mathrm{E}-01)\end{array}$ & $=$ \\
\hline F15 & $\begin{array}{c}1.16 \mathrm{E}+01 \\
(1.47 \mathrm{E}+00)\end{array}$ & $\begin{array}{c}4.23 \mathrm{E}+01 \\
(2.15 \mathrm{E}+01)\end{array}$ & + & $\begin{array}{c}1.75 \mathrm{E}+01 \\
(1.18 \mathrm{E}+01)\end{array}$ & + & $\begin{array}{c}2.26 \mathrm{E}+01 \\
(2.77 \mathrm{E}+01)\end{array}$ & + & $\begin{array}{c}1.50 \mathrm{E}+01 \\
(2.99 \mathrm{E}+00)\end{array}$ & + \\
\hline F16 & $\begin{array}{c}1.13 \mathrm{E}+01 \\
(3.54 \mathrm{E}-01)\end{array}$ & $\begin{array}{c}1.14 \mathrm{E}+01 \\
(7.11 \mathrm{E}-01)\end{array}$ & $=$ & $\begin{array}{c}1.23 \mathrm{E}+01 \\
(7.57 \mathrm{E}-01)\end{array}$ & + & $\begin{array}{c}1.27 \mathrm{E}+01 \\
(6.80 \mathrm{E}-01)\end{array}$ & + & $\begin{array}{c}1.14 \mathrm{E}+01 \\
(9.77 \mathrm{E}-01)\end{array}$ & $=$ \\
\hline F17 & $\begin{array}{c}6.04 \mathrm{E}+04 \\
(4.10 \mathrm{E}+04)\end{array}$ & $\begin{array}{c}7.97 \mathrm{E}+05 \\
(5.26 \mathrm{E}+05)\end{array}$ & + & $\begin{array}{c}8.74 \mathrm{E}+04 \\
(5.24 \mathrm{E}+04)\end{array}$ & + & $\begin{array}{c}2.60 \mathrm{E}+05 \\
(6.38 \mathrm{E}+05)\end{array}$ & + & $\begin{array}{c}5.10 \mathrm{E}+05 \\
(4.62 \mathrm{E}+05)\end{array}$ & + \\
\hline F18 & $\begin{array}{c}3.31 \mathrm{E}+03 \\
(3.95 \mathrm{E}+03)\end{array}$ & $\begin{array}{c}3.67 \mathrm{E}+03 \\
(4.25 \mathrm{E}+03)\end{array}$ & $=$ & $\begin{array}{c}2.85 \mathrm{E}+03 \\
(3.41 \mathrm{E}+03)\end{array}$ & $=$ & $\begin{array}{c}3.70 \mathrm{E}+03 \\
(3.68 \mathrm{E}+03)\end{array}$ & $=$ & $\begin{array}{c}1.78 \mathrm{E}+03 \\
(2.79 \mathrm{E}+03)\end{array}$ & $=$ \\
\hline F19 & $\begin{array}{c}1.02 \mathrm{E}+01 \\
(1.48 \mathrm{E}+01)\end{array}$ & $\begin{array}{c}4.62 \mathrm{E}+01 \\
(4.40 \mathrm{E}+01)\end{array}$ & + & $\begin{array}{c}1.59 \mathrm{E}+01 \\
(2.24 \mathrm{E}+01)\end{array}$ & $=$ & $\begin{array}{c}2.10 \mathrm{E}+01 \\
(2.43 \mathrm{E}+01)\end{array}$ & + & $\begin{array}{c}8.59 \mathrm{E}+00 \\
(1.19 \mathrm{E}+00)\end{array}$ & - \\
\hline F20 & $\begin{array}{c}3.32 \mathrm{E}+03 \\
(4.20 \mathrm{E}+03)\end{array}$ & $\begin{array}{c}4.89 \mathrm{E}+04 \\
(2.72 \mathrm{E}+04)\end{array}$ & + & $\begin{array}{c}1.11 \mathrm{E}+04 \\
(8.53 \mathrm{E}+03)\end{array}$ & + & $\begin{array}{c}1.46 \mathrm{E}+04 \\
(1.01 \mathrm{E}+04)\end{array}$ & + & $\begin{array}{c}2.70 \mathrm{E}+02 \\
(2.70 \mathrm{E}+02)\end{array}$ & - \\
\hline F21 & $\begin{array}{c}4.22 \mathrm{E}+04 \\
(4.53 \mathrm{E}+04)\end{array}$ & $\begin{array}{c}2.86 \mathrm{E}+05 \\
(2.28 \mathrm{E}+05)\end{array}$ & + & $\begin{array}{c}4.91 \mathrm{E}+04 \\
(3.82 \mathrm{E}+04)\end{array}$ & $=$ & $\begin{array}{c}1.09 \mathrm{E}+05 \\
(7.21 \mathrm{E}+04)\end{array}$ & + & $\begin{array}{c}2.31 \mathrm{E}+04 \\
(1.61 \mathrm{E}+04)\end{array}$ & - \\
\hline F22 & $\begin{array}{c}2.86 \mathrm{E}+02 \\
(1.17 \mathrm{E}+02)\end{array}$ & $\begin{array}{c}5.92 \mathrm{E}+02 \\
(2.17 \mathrm{E}+02)\end{array}$ & + & $\begin{array}{c}3.77 \mathrm{E}+02 \\
(2.15 \mathrm{E}+02)\end{array}$ & $=$ & $\begin{array}{c}4.19 \mathrm{E}+02 \\
(2.10 \mathrm{E}+02)\end{array}$ & + & $\begin{array}{c}2.94 \mathrm{E}+02 \\
(1.43 \mathrm{E}+02)\end{array}$ & $=$ \\
\hline $\mathrm{F} 23$ & $\begin{array}{c}3.15 \mathrm{E}+02 \\
(6.62 \mathrm{E}-12)\end{array}$ & $\begin{array}{c}3.20 \mathrm{E}+02 \\
(4.14 \mathrm{E}+00)\end{array}$ & + & $\begin{array}{c}3.15 \mathrm{E}+02 \\
(4.33 \mathrm{E}-10)\end{array}$ & + & $\begin{array}{c}3.15 \mathrm{E}+02 \\
(4.47 \mathrm{E}-05)\end{array}$ & + & $\begin{array}{c}3.15 \mathrm{E}+02 \\
(3.95 \mathrm{E}-13)\end{array}$ & - \\
\hline F24 & $\begin{array}{c}2.32 \mathrm{E}+02 \\
(6.36 \mathrm{E}+00)\end{array}$ & $\begin{array}{c}2.61 \mathrm{E}+02 \\
(1.03 \mathrm{E}+01)\end{array}$ & + & $\begin{array}{c}2.47 \mathrm{E}+02 \\
(7.45 \mathrm{E}+00)\end{array}$ & + & $\begin{array}{c}2.46 \mathrm{E}+02 \\
(7.32 \mathrm{E}+00)\end{array}$ & + & $\begin{array}{c}2.28 \mathrm{E}+02 \\
(3.98 \mathrm{E}+00)\end{array}$ & - \\
\hline F25 & $\begin{array}{c}2.06 \mathrm{E}+02 \\
(1.87 \mathrm{E}+00)\end{array}$ & $\begin{array}{c}2.24 \mathrm{E}+02 \\
(6.15 \mathrm{E}+00)\end{array}$ & + & $\begin{array}{c}2.10 \mathrm{E}+02 \\
(5.01 \mathrm{E}+00)\end{array}$ & + & $\begin{array}{c}3.03 \mathrm{E}+02 \\
(8.39 \mathrm{E}+01)\end{array}$ & + & $\begin{array}{c}2.11 \mathrm{E}+02 \\
(2.52 \mathrm{E}+00)\end{array}$ & + \\
\hline F26 & $\begin{array}{c}1.06 \mathrm{E}+02 \\
(2.37 \mathrm{E}+01)\end{array}$ & $\begin{array}{c}1.63 \mathrm{E}+02 \\
(4.88 \mathrm{E}+01)\end{array}$ & + & $\begin{array}{c}1.32 \mathrm{E}+02 \\
(4.63 \mathrm{E}+01)\end{array}$ & + & $\begin{array}{c}2.56 \mathrm{E}+02 \\
(1.16 \mathrm{E}+02)\end{array}$ & + & $\begin{array}{c}1.08 \mathrm{E}+02 \\
(2.74 \mathrm{E}+01)\end{array}$ & $=$ \\
\hline F27 & $\begin{array}{c}4.98 \mathrm{E}+02 \\
(1.48 \mathrm{E}+02)\end{array}$ & $\begin{array}{c}7.51 \mathrm{E}+02 \\
(2.79 \mathrm{E}+02)\end{array}$ & + & $\begin{array}{c}7.20 \mathrm{E}+02 \\
(1.33 \mathrm{E}+02)\end{array}$ & + & $\begin{array}{c}7.32 \mathrm{E}+02 \\
(2.92 \mathrm{E}+02)\end{array}$ & + & $\begin{array}{c}5.43 \mathrm{E}+02 \\
(1.74 \mathrm{E}+02)\end{array}$ & + \\
\hline F28 & $\begin{array}{c}9.75 \mathrm{E}+02 \\
(5.66 \mathrm{E}+01)\end{array}$ & $\begin{array}{c}2.40 \mathrm{E}+03 \\
(5.58 \mathrm{E}+02)\end{array}$ & + & $\begin{array}{c}1.23 \mathrm{E}+03 \\
(2.42 \mathrm{E}+02)\end{array}$ & + & $\begin{array}{c}2.15 \mathrm{E}+03 \\
(1.78 \mathrm{E}+03)\end{array}$ & + & $\begin{array}{c}1.03 \mathrm{E}+03 \\
(1.35 \mathrm{E}+02)\end{array}$ & $=$ \\
\hline F29 & $\begin{array}{c}1.36 \mathrm{E}+03 \\
(3.71 \mathrm{E}+02)\end{array}$ & $\begin{array}{c}1.39 \mathrm{E}+07 \\
(2.55 \mathrm{E}+07)\end{array}$ & + & $\begin{array}{c}1.36 \mathrm{E}+03 \\
(3.91 \mathrm{E}+02)\end{array}$ & $=$ & $\begin{array}{c}1.23 \mathrm{E}+07 \\
(8.79 \mathrm{E}+07)\end{array}$ & $=$ & $\begin{array}{c}6.68 \mathrm{E}+05 \\
(2.30 \mathrm{E}+06)\end{array}$ & + \\
\hline F30 & $\begin{array}{c}2.13 \mathrm{E}+03 \\
(7.60 \mathrm{E}+02)\end{array}$ & $\begin{array}{c}2.35 \mathrm{E}+04 \\
(1.27 \mathrm{E}+04)\end{array}$ & + & $\begin{array}{c}2.82 \mathrm{E}+03 \\
(8.58 \mathrm{E}+02)\end{array}$ & + & $\begin{array}{c}3.13 \mathrm{E}+03 \\
(8.88 \mathrm{E}+02)\end{array}$ & + & $\begin{array}{c}3.06 \mathrm{E}+03 \\
(9.45 \mathrm{E}+02)\end{array}$ & + \\
\hline B-S-W & & $23-5-2$ & & $20-8-2$ & & $25-4-1$ & & $12-9-9$ & \\
\hline
\end{tabular}

,$+=$ and - symbolize VB-mDE being better than, similar to, or worse than its competitor, respectively. 


\section{References}

[1] S. Das, S.S. Mullick and P.N. Suganthan, Recent advances in differential evolutionan updated survey, Swarm and Evolutionary Computation 27 (2016), 1-30.

[2] X. Chen, W. Du and F. Qian, Solving chemical dynamic optimization problems with ranking-based differential evolution algorithms, Chinese Journal of Chemical Engineering 24(11) (2016), 1600-1608.

[3] D. Zou, S. Li, G.G. Wang, Z. Li and H. Ouyang, An improved differential evolution algorithm for the economic load dispatch problems with or without valve-point effects, Applied Energy 181 (2016), 375390.

[4] Q.K. Pan, L. Wang, L. Gao and W.D. Li, An effective hybrid discrete differential evolution algorithm for the flow shop scheduling with intermediate buffers, Information Sciences 181(3)(2011), 668-685.

[5] J. Ronkkonen, S. Kukkonen and K.V. Price, Real-parameter optimization with differential evolution, in: 2005 IEEE congress on evolutionary computation, IEEE, 2005, pp.506-513.

[6] C. Brown, Y. Jin, M. Leach and M. Hodgson, $\mu$ JADE: adaptive differential evolution with a small population, Soft computing 20(10)(2016), 4111-4120.

[7] H. Salehinejad and S. Talebi, Dynamic fuzzy logic-ant colony system-based route selection system, Applied Computational Intelligence and Soft Computing, (2010), Article ID 428270, 13 pages.

[8] S. Rahnamayan and H.R. Tizhoosh. Image thresholding using micro opposition-based differential evolution (micro-ODE), in: 2008 IEEE Congress on Evolutionary Computation, IEEE, 2008, pp.1409-1416.

[9] X. Ren, Z. Chen and Z. Ma, Differential evolution using smaller population, in: 2010 Second International Conference on Machine Learning and Computing, IEEE, 2010, pp. 76-80.

[10] I. Fajfar, T. Tuma, J. Puhan, J. Olensek and A. Burmen, Towards smaller populations in differential evolution, J Microelectron Electron Compon Mater 42 (2012), 152-163.

[11] M. Olguin-Carbajal, E. Alba and J. Arellano-Verdejo, Micro-differential evolution with local search for high dimensional problems, in: 2013 IEEE Congress on Evolutionary Computation, IEEE, 2013, pp. 48-54.

[12] Y.E. Yildiz and A.O. Topal, Large scale continuous global optimization based on micro differential evolution with local directional search, Information Sciences 477 (2019),533-544.

[13] H. Salehinejad, S. Rahnamayan and H.R. Tizhoosh, Micro-differential evolution: Diversity enhancement and a comparative study, Applied Soft Computing 52 (2017), 812-833.

[14] H. Salehinejad, S. Rahnamayan and H.R. Tizhoosh, Exploration enhancement in ensemble microdifferential evolution, in: IEEE Congress on Evolutionary Computation (CEC), IEEE, 2016, pp. 63-70.

[15] R.D. Al-Dabbagh, F. Neri, N. Idris and M.S. Baba, Algorithmic design issues in adaptive differential evolution schemes: Review and taxonomy, Swarm and Evolutionary Computation 43 (2018), 284-311.

[16] R. Tanabe and A. Fukunaga, Reviewing and benchmarking parameter control methods in differential evolution, IEEE Transactions on Cybernetics 50(3)(2019),1170-1184.

[17] Y. Wang, H.X. Li, T. Huang and L. Li, Differential evolution based on covariance matrix learning and bimodal distribution parameter setting, Applied Soft Computing 18 (2014), 232-247.

[18] H. Salehinejad, S. Rahnamayan and H.R. Tizhoosh, Opposition-based ensemble micro-differential evolution, in: 2017 IEEE Symposium Series on Computational Intelligence (SSCI), IEEE, 2017, pp.1-8.

[19] J. Zhang and A.C. Sanderson, JADE: adaptive differential evolution with optional external archive, IEEE Transactions on Evolutionary Computation 13(5) (2009), 945-958.

[20] Y.L. Li, Z.H. Zhan, Y.J. Gong and J. Zhang, Fast micro-differential evolution for topological active net optimization, IEEE Transactions on Cybernetics 46 (6) (2015), 1411-1423.

[21] E. Mininno, F. Neri, F. Cupertino and D. Naso, Compact differential evolution, IEEE Transactions on Evolutionary Computation 15 (1) (2010), 32-54.

[22] J. Brest, S. Greiner, B. Boskovic and V. Zumer, Self-adapting control parameters in differential evolution: A comparative study on numerical benchmark problems, IEEE Transactions on Evolutionary Computation 10 (6) (2006), 646-657.

[23] J.J. Liang, B.Y. Qu and P.N. Suganthan, Problem definitions and evaluation criteria for the CEC 2014 special session and competition on single objective real-parameter numerical optimization, Computational Intelligence Laboratory, Zhengzhou University, China and Technical Report, Nanyang Technological University, Singapore (2013), 635.

[24] J. Alcal-Fdez, L. Snchez, S. Garca, M. J. del Jesus, S. Ventura, J. M. Garrell, J. Otero, C. Romero, J. Bacardit, V. M. Rivas, J. C. Fernndez and F. Herrera, KEEL: a software tool to assess evolutionary algorithms for data mining problems, Soft Computing 13 (3) (2009), 307-318. 
[25] A.K. Qin, V.L. Huang and P.N. Suganthan. Differential evolution algorithm with strategy adaptation for global numerical optimization, IEEE transactions on Evolutionary Computation 13(2) (2008), 398-417.

\section{Authors' Bios}

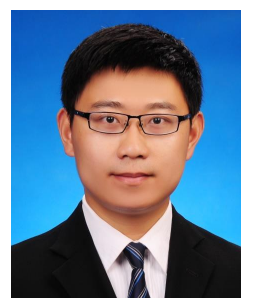

Xu Chen is an Associate Professor in School of Electrical and Information Engineering at Jiangsu University, China. He received the Ph.D. degree in Control Science and Engineering from East China University of Science and Technology, China. His research interests focus on evolutionary computation techniques and power system optimization.

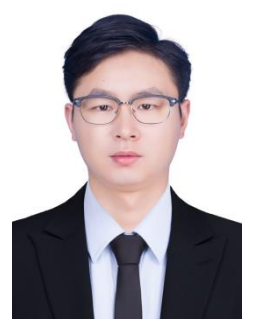

Xueliang Miao received the bachelor's degree in Electrical Engineering \& Automation from Jiangsu University in 2017, and received the master's degree in Control Engineering from Jiangsu University in 2020. He is now an engineer of China nuclear power technology corporation, LTD. His research interests focus on intelligent optimization algorithms and nondestructive testing.

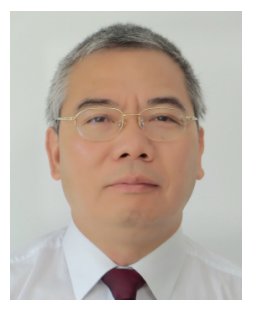

Hugo Tianfield is a Professor of Computing at Glasgow Caledonian University, Glasgow, United Kingdom from March 2001. Prof Tianfield is extensively involved in professional activities. He is member of EPSRC Peer College UK, Chair of the Technical Committee on Cyber-Physical Cloud Systems with the IEEE Systems, Man, and 
January 2020

Cybernetics Society, Editor-in-Chief of Multiagent and Grid Systems -An International Journal, and Associate Editor of IEEE Transactions on Systems, Man, and CyberneticsSystems. Prof Tianfield is Director of AI Research Lab. His research areas include Big Data, Cloud Computing, Cyber Security, and Internet of Things. He is (co-)author of about 200 research publications in refereed journals and conferences, and is a frequent invited speaker at international forums and institutions worldwide. 